\title{
DIFFERENTIAL EFFECTS OF DEXAMETHASONE ON THE CHONDROGENESIS OF MESENCHYMAL STROMAL CELLS: INFLUENCE OF MICROENVIRONMENT, TISSUE ORIGIN AND GROWTH FACTOR
}

\author{
N. Shintani and E.B. Hunziker* \\ Center of Regenerative Medicine for Skeletal Tissues, Department of Clinical Research, \\ University of Bern, Bern, Switzerland
}

\begin{abstract}
Mesenchymal stromal cells (MSCs), which reside within various tissues, are utilized in the engineering of cartilage tissue. Dexamethasone (DEX) - a synthetic glucocorticoid - is almost invariably applied to potentiate the growthfactor-induced chondrogenesis of MSCs in vitro, albeit that this effect has been experimentally demonstrated only for transforming-growth-factor-beta (TGF- $\beta$ )-stimulated bone-marrow-derived MSCs. Clinically, systemic glucocorticoid therapy is associated with untoward side effects (e.g., bone loss and increased susceptibility to infection). Hence, the use of these agents should be avoided or limited. We hypothesize that the influence of DEX on the chondrogenesis of MSCs depends upon their tissue origin and microenvironment [absence or presence of an extracellular matrix (ECM)], as well as upon the nature of the growth factor. We investigated its effects upon the TGF- $\beta 1$ - and bone-morphogenetic-protein 2 (BMP-2)induced chondrogenesis of MSCs as a function of tissue source (bone marrow vs. synovium) and microenvironment [cell aggregates (no ECM) vs. explants (presence of a natural ECM)]. In aggregates of bone-marrow-derived MSCs, DEX enhanced TGF- $\beta 1$-induced chondrogenesis by an up-regulation of cartilaginous genes, but had little influence on the BMP-2-induced response. In aggregates of synovial MSCs, DEX exerted no remarkable effect on either TGF- $\beta 1$ - or BMP-2-induced chondrogenesis. In synovial explants, DEX inhibited BMP-2-induced chondrogenesis almost completely, but had little impact on the TGF- $\beta 1$ induced response. Our data reveal that steroids are not indispensable for the chondrogenesis of MSCs in vitro. Their influence is context dependent (tissue source of the MSCs, their microenvironment and the nature of the growth factor). This finding has important implications for MSCbased approaches to cartilage repair.
\end{abstract}

Keywords: Mesenchymal stromal cells, dexamethasone, synovium, bone marrow, chondrogenesis

*Address for correspondence:

Ernst B. Hunziker

Center of Regenerative Medicine for Skeletal Tissues, Department of Clinical Research, University of Bern, Murtenstrasse 35, P.O. Box 54, 3010 Bern, Switzerland Telephone Number: +41316328685 FAX Number: +41316324999 E-mail: ernst.hunziker@dkf.unibe.ch

\section{Introduction}

Owing to their self-renewal capacity, chondrogenic potential and accessibility, mesenchymal stromal cells (MSCs) are an attractive option for the engineering of cartilage tissue. MSCs were originally isolated from rat bone marrow (Friedenstein et al., 1966), and they are known to reside within many mammalian tissues, such as synovium, trabecular bone, periosteum, articular cartilage, muscle and fat (De Bari et al., 2001b; Erickson et al., 2002; Nöth et al., 2002; Zuk et al., 2002; Alsalameh et al., 2004; Sinanan et al., 2004; Mastrogiacomo et al., 2005; De Bari et al., 2006). Under appropriate stimulation conditions in vitro, MSCs can differentiate into several types of mesenchymal tissue, including bone, cartilage and fat.

In most in-vitro studies, dexamethasone (DEX) is used in conjunction with transforming growth factorbeta1 (TGF- $\beta 1$ ), or one of its isoforms, to drive the differentiation of MSCs towards chondrogenesis. The chondrogenic effects of DEX were first reported for lapine bone-marrow-derived MSCs (Johnstone et al., 1998). And, in a study with human bone-marrow-derived MSCs, TGF- $\beta 1$ induced chondrogenesis only in the presence of DEX (Yoo et al., 1998). Subsequently, TGF-ß1 and DEX were concomitantly employed to elicit the chondrogenic differentiation of MSCs of diverse tissue origins, including fat (Erickson et al., 2002), periosteum (De Bari et al., 2001a), synovium (De Bari et al., 2001b), trabecular bone (Nöth et al., 2002) and muscle (Mastrogiacomo et al., 2005). However, the authors of the cited publications did not experimentally ascertain whether DEX was indeed necessary for the chondrogenesis of MSCs.

In a previous study, we demonstrated that BMP-2 could induce the chondrogenesis of bovine synovial explants in the absence of DEX (Shintani and Hunziker, 2007). Indeed, in its presence, metachromasia of the extracellular matrix (ECM) did not occur after staining with Toluidine Blue. DEX also suppresses the BMP-2induced chondrogenesis of isolated, alginate-cultured bovine and human synovial MSCs (Park et al., 2005; Kurth et al., 2007). These findings point to the existence of differences in the reactivity of synovial and bone-marrowderived MSCs to DEX. However, several issues await clarification. In these previous studies of ours, the synovial MSCs were surrounded either by their native ECM (explant cultures) or by an artificial one (alginate). In the studies by other investigators, the bone-marrow-derived MSCs were cultured in the absence of an ECM, namely, under high-density conditions as pellets (Johnstone et al., 1998; Yoo et al., 1998). And apart from this variable, the 
nature of the stimulating agent (BMP-2 or TGF- $\beta 1$ ) also differed.

The clinical application of steroid hormones such as DEX is associated not only with many beneficial (e.g., antiinflammatory and immunosuppressive) effects, but also with numerous adverse ones (e.g., bone loss and increased susceptibility to infection) (Kleiman and Tuckermann, 2007). In the context of clinical tissue engineering, these undesired side effects cannot be ignored. Since most of the untoward effects of DEX are associated with its systemic administration, a local delivery of the drug might offer a means of attenuating them ( $\mathrm{Na}$ et al., 2006; Nuttelman et al., 2006). Nevertheless, the unnecessary use of DEX should be avoided. We hypothesize that the potentiating effects of DEX on chondrogenesis depend not only upon the choice of the growth factor with which it is coupled, but also upon the tissue origin of the MSCs and their microenvironment (e.g., their numerical density and the nature of their ECM). Indeed, we conceive that, under appropriate conditions, it may even be possible to dispense with the agent altogether in tissue-engineering approaches to cartilage repair. It was the purpose of the present study to clarify this issue.

To define the impact of the aforementioned parameters on the effects of DEX, we established the following setups: bovine synovial explants; aggregates of isolated bovine synovial MSCs; and aggregates of isolated bovine bone-marrow-derived MSCs. The first case represents one that is close to the native state, namely, the MSCs are present at low numerical densities and are surrounded by their natural ECM. In the second and third cases, the MSCs are of different tissue origins and are cultured under high-density conditions in the absence of an ECM. In each set-up, either TGF- $\beta 1$ or BMP- 2 was used as the chondrogenic agent. Our study revealed the effects of DEX on the chondrogenesis of MSCs to be influenced by their microenvironment, their tissue source and the nature of the growth factor.

\section{Materials and Methods}

\section{Preparation and culturing of synovial explants}

Synovial tissue was harvested from the metacarpal joints of 4-month-old bovine calves within $24 \mathrm{~h}$ of slaughtering. After washing, the material was cut into slender strips (3-5 $\mathrm{mm}$ in width $\mathrm{x} 5-7 \mathrm{~mm}$ in length), the wet weights of which were measured under sterile conditions. The explants were sandwiched between two layers of agarose to prevent cell outgrowth (Shintani and Hunziker, 2007). Each explant was covered with $1 \mathrm{~mL}$ of serum-free medium [high-glucose DMEM (Invitrogen, Paisley, UK) containing $1 \%$ ITS $+{ }^{\mathrm{TM}}$ Premix (BD Biosciences, Bedford, MA, USA), $1 \mathrm{mM}$ proline, ascorbic acid $(50 \mu \mathrm{g} / \mathrm{mL})$ and gentamycin $(50 \mu \mathrm{g} / \mathrm{mL})]$. Chondrogenesis was induced by adding either human recombinant TGF- $\beta 1$ ( $10 \mathrm{ng} / \mathrm{mL}$; Peprotech, Rocky Hill, NJ) or BMP-2 [200 ng/mL; a generous gift from Pfizer (formerly Wyeth), New York City, NY, USA] to the culture medium, in the absence or presence of DEX (100 nM; Sigma-Aldrich, St Louis, MO, USA). The growth factors and DEX were introduced every 2 days when the medium was changed. The medium was supplemented with fresh ascorbic acid $(25 \mu \mathrm{g} / \mathrm{mL})$ on a daily basis. The synovial explants were cultured for 2 or 4 weeks at $37^{\circ} \mathrm{C}$ in a humidified atmosphere containing $5 \% \mathrm{CO}_{2}$.

\section{Isolation and expansion of synovial and bone- marrow-derived MSCs}

Synovial tissue was harvested as described above. The material was minced and then digested first (for $1 \mathrm{~h}$ ) with $1 \%$ pronase (Roche Diagnostics, Basel, Switzerland) in high-glucose DMEM containing gentamycin [DMEM/ gentamycin $(50 \mu \mathrm{g} / \mathrm{mL})]$ and then (overnight) with $0.14 \%$ collagenase (Invitrogen) in DMEM/gentamycin (Shintani and Hunziker, 2007). The supernatant was strained through a nylon filter with a pore diameter of $120 \mu \mathrm{m}$ (Millipore AG, Volketswil, Switzerland) to remove undigested tissue. The cells were collected by centrifugation, washed twice and resuspended in growth medium (DMEM/gentamycin containing $10 \%$ fetal bovine serum).

Bone-marrow cells were harvested from the metacarpal bones of 4-month-old bovine calves within $24 \mathrm{~h}$ of slaughtering. The marrow was removed and strained through a nylon filter with a pore diameter of $120 \mu \mathrm{m}$ to remove adipose tissue. The cells were collected by centrifugation, washed twice and suspended in growth medium.

The cell suspensions were applied to 100 -mm-diameter cell culture dishes and incubated at $37{ }^{\circ} \mathrm{C}$ in a humidified atmosphere containing $5 \% \mathrm{CO}_{2}$. After 2-3 days, the medium was changed to remove non-adherent cells. The attached cells were further cultured until they had attained a state of near confluence. For expansion, the near-confluent cells were harvested by treatment with $0.25 \%$ trypsin/ 1 mM EDTA and replated at a numerical density of $2-3 \times 10^{5}$ per dish (first passage). The growth medium was replaced every 2-3 days until the cells had attained a state of near confluence.

\section{Micromass cultures}

Aggregates of synovial and bone-marrow-derived MSCs were prepared by culturing them under micromass conditions, according to a modified version of published protocols (De Bari et al., 2001b; Park et al., 2005; Shintani and Hunziker, 2007). Specifically, the first-passage MSCs were suspended at a numerical density of $2 \times 10^{7}$ per $\mathrm{mL}$; $50-\mu \mathrm{L}$ aliquots $(\sim 1$ million cells per aggregate culture) were applied to 12-well tissue-culture plates, which were incubated for $4 \mathrm{~h}$ at $37{ }^{\circ} \mathrm{C}$ in a humidified atmosphere containing $5 \% \mathrm{CO}_{2} .2 \mathrm{~mL}$ of serum-free medium were then added. Chondrogenesis was induced and the micromass cultures were maintained for 2 or 4 weeks as described above for synovial explants.

\section{Histology and morphometry}

After culturing, the synovial explants and the aggregates of synovial or bone-marrow-derived MSCs were chemically fixed in phosphate-buffered saline ( $\mathrm{pH} 7.4)$ containing 2 $\%$ formaldehyde and then embedded in paraffin. $5-\mu \mathrm{m}-$ thick sections of the embedded materials were prepared and stained with $1 \%$ Toluidine Blue $(\mathrm{pH} 2.5)$ for the histological detection of sulfated proteoglycans within a 
cartilaginous matrix (an indirect measure of chondrogenic differentiation). The sections were evaluated in a Nikon Eclipse E1000 light microscope using a DXM 1200F digital camera and Eclipsenet software (Nikon, Tokyo, Japan). The volume fraction of metachromasia in synovial explants was assessed morphometrically, as previously described (Shintani and Hunziker, 2007).

\section{Immunohistochemistry}

Immunohistochemistry was performed on 5 - $\mu$ m-thick paraffin-embedded sections through synovial explants and aggregates of synovial or bone-marrow-derived MSCs using murine monoclonal antibodies against type-II collagen (clone CII C1, Hybridoma Bank, Iowa City, IA, USA) and aggrecan (HAG7D4, Serotec, Oxford, UK), as previously described (Shintani and Hunziker, 2007). Deparaffinized sections were first treated with hyaluronidase, then with $3 \%$ skimmed bovine milk containing $1.5 \%$ equine serum to block non-specific antibody reactivity, and finally with one of the primary antibodies $\left(60 \mathrm{~min}\right.$ at $\left.37^{\circ} \mathrm{C}\right)$. A biotinylated form of an equine, anti-murine secondary antibody (Vector Laboratories, Burlingame, CA, USA) was used to detect the antibodies against type-II collagen and aggrecan. Endogenous peroxidase activity was blocked with hydrogen peroxide. Immunoreactivity was enhanced by applying the avidin-biotin-peroxidase complex (Vector Laboratories). Cell nuclei were counterstained with hematoxylin. The sections were evaluated and photographed in a Nikon Eclipse E1000 light microscope.

\section{Measurement of glycosaminoglycan (GAG)-content}

Before culturing, the initial wet weight of each explant was measured under sterile conditions. After culturing, the tissue explants and the cell aggregates were digested (overnight at $60^{\circ} \mathrm{C}$ ) with $0.1 \%$ papain and $0.1 \%$ proteinase $\mathrm{K}$ in $1 \mathrm{mM} \mathrm{CaCl}_{2}$, which was buffered with $10 \mathrm{mM}$ TRIS$\mathrm{HCl}$ (pH 8) (Roche et al., 2001). The DNA-content of the digests was measured spectrofluorometrically using the High Sensitivity Quant-iTT ${ }^{\mathrm{TM}}$ DNA Assay Kit (Molecular Probes, Eugene, OR, USA). The weight of DNA (in ng) was expressed per $\mathrm{mg}$ of the initial wet explant weight or per MSC-aggregate. The glycosaminoglycan (GAG)content of the digests was determined colorimetrically after treatment with 1,9-dimethylmethylene Blue (SERVA Electrophoresis, Heidelberg, Germany) (Farndale et al., 1986). Chondroitin sulfate (Sigma-Aldrich) was used as a standard. The weight of GAGs (in $\mu \mathrm{g}$ ) was expressed per $\mu \mathrm{g}$ of DNA, as well as per mg of the initial wet explant weight and per MSC aggregate.

\section{RNA extraction, reverse transcription and real-time PCR}

After culturing, the tissue explants and the cell aggregates were stored in RNAlater ${ }^{\mathrm{TM}}$ (Qiagen, Hilden, Germany) at $-70{ }^{\circ} \mathrm{C}$. Isolation of the RNA, reverse transcription and realtime PCR were performed as previously described (Shintani et al., 2007). The cultured samples were first pulverized in a freezer mill and then dissolved in QIAzol ${ }^{\mathrm{TM}} \mathrm{Lysis}$ Reagent (Qiagen). RNA was isolated using the RNeasy Micro Kit (Qiagen). The RNA derived from each sample was reverse transcribed using the Reverse Transcription System (Promega, Madison, WI, USA) and then subjected to real-time PCR (Applied Biosystems 7900 instrument, Foster City, CA, USA). A calibrator was prepared from a mixture of the RNA that was isolated from the cartilage and synovium of bovine metacarpal joints. Primers and probes for bovine collagen types I, II, IX, X and XI, aggrecan, cartilage oligomeric matrix protein (COMP), Sox9 and 18S ribosomal RNA (rRNA) were generated as previously described (Shintani et al., 2007). Specific primers and probes for bovine link protein [hyaluronan and proteoglycan link protein 1 (HAPLN1)] (forward primer: 5'-GAAGGCGCTGCAGTCCTAGC-3'; reverse primer: 5'-GGCACGCTCAGTTGTATGCTCT-3'; probe: 6-FAM5'-CAGTGCGCTTCGTGGGTTTCCCA-3'-BHQ-1) were designed using Primer3 software (http://frodo.wi.mit. edu/primer3/). Gene expression was normalized to the level of $18 \mathrm{~S}$ rRNA using the formula $2^{-\Delta \mathrm{CT}}$, where $\mathrm{C}_{\mathrm{T}}$ is the threshold cycle and $\Delta \mathrm{C}_{\mathrm{T}}=\mathrm{C}_{\mathrm{T}}$ (target gene $)-\mathrm{C}_{\mathrm{T}}(18 \mathrm{~S}$ rRNA). For each gene, the normalized mRNA level in each sample (explant or aggregate) was calculated relative to that in the calibrator (mixture of uncultured cartilage and synovium) using the formula $2^{-\Delta \Delta C \mathrm{~T}}$, where $\Delta \Delta \mathrm{C}_{\mathrm{T}}=\Delta \mathrm{C}_{\mathrm{T}}$ (sample) $-\Delta \mathrm{C}_{\mathrm{T}}$ (calibrator).

\section{Statistical analysis}

Numerical data are represented as mean values together with the standard error of the mean (SEM). Comparisons between two sets of data were statistically evaluated by an analysis of variances (ANOVA). Comparisons between multiple groups were evaluated by applying Dunnett's multiple comparison test. Statistical analyses were performed using SPSS software, version 11. 04 (SPSS Inc., Chicago, IL, USA). Statistical significance was set at a $p$-value of $<0.05$.

\section{Results}

\section{DEX inhibits the growth-factor-induced deposition} of a cartilage-like matrix in synovial explants: partially after stimulation with TGF-ß1, and almost completely after stimulation with BMP-2

To ascertain whether the effects of DEX on the chondrogenic differentiation of synovial explants depends upon the nature of the growth factor, explants were exposed to either TGF- $\beta 1$ (10 ng/mL) or BMP-2 (200 ng/mL), in the absence or presence of DEX (100 nM), for 2 or 4 weeks. In the absence of a growth factor, the ECM of synovial explants manifested no discernible metachromasia after staining with Toluidine Blue, irrespective of the absence or presence of DEX (Fig. 1A). After stimulation with TGF- $\beta 1$ for 4 weeks in the absence of DEX, the ECM of synovial explants manifested intense metachromasia (Fig. 1A). When DEX was included in the culture medium, TGF- $\beta 1$ induced weak metachromasia (Fig. 1A). After stimulation with BMP-2 for 4 weeks in the absence of DEX, the ECM of synovial explants manifested intense metachromasia and the cells had differentiated into chondrocytes, which were surrounded by pericellular lacunae (Fig. 1A). 


\section{Synovial Explants}

\section{A Toluidine-Blue staining (metachromasia)}
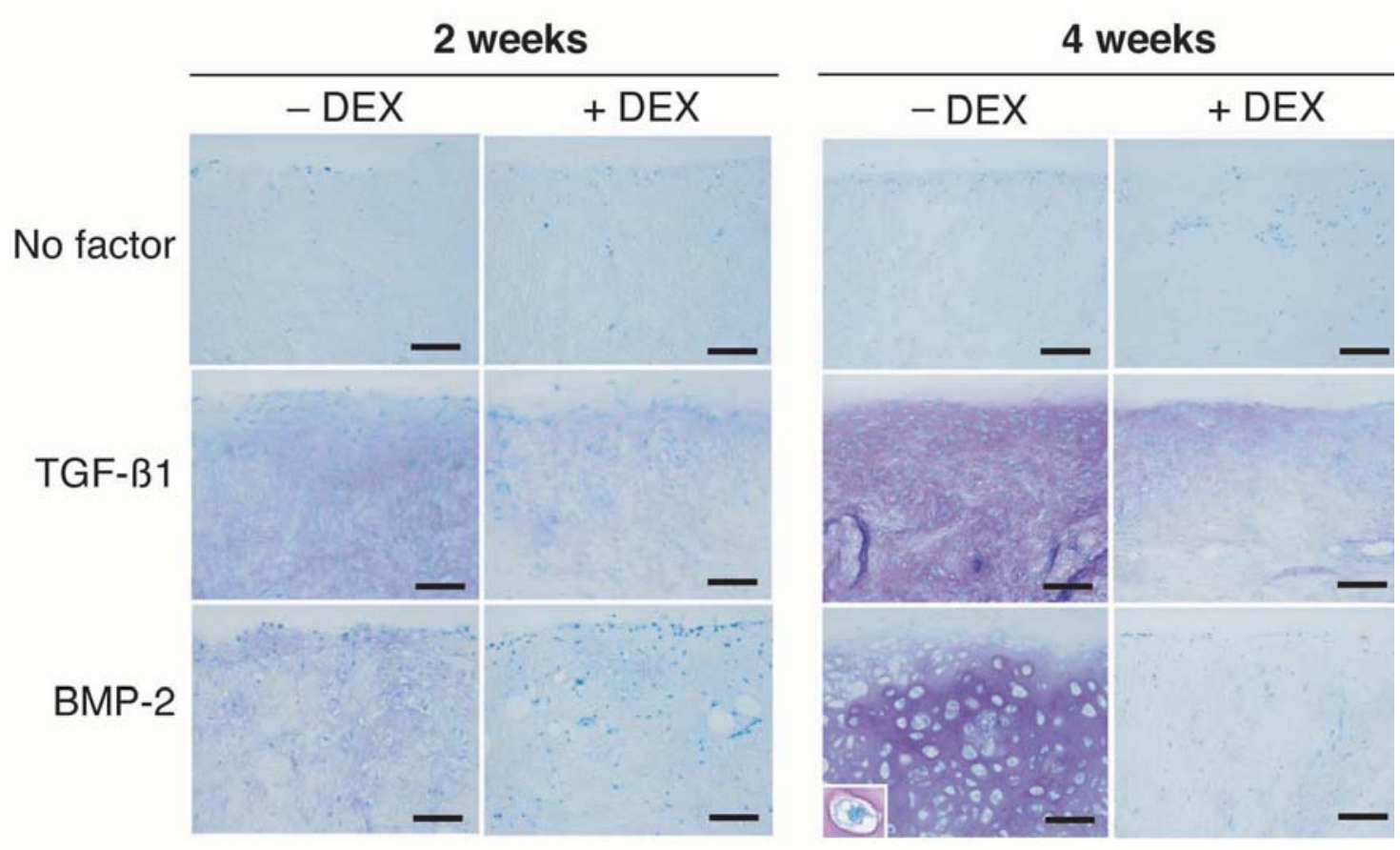

\section{B Immunohistochemistry}
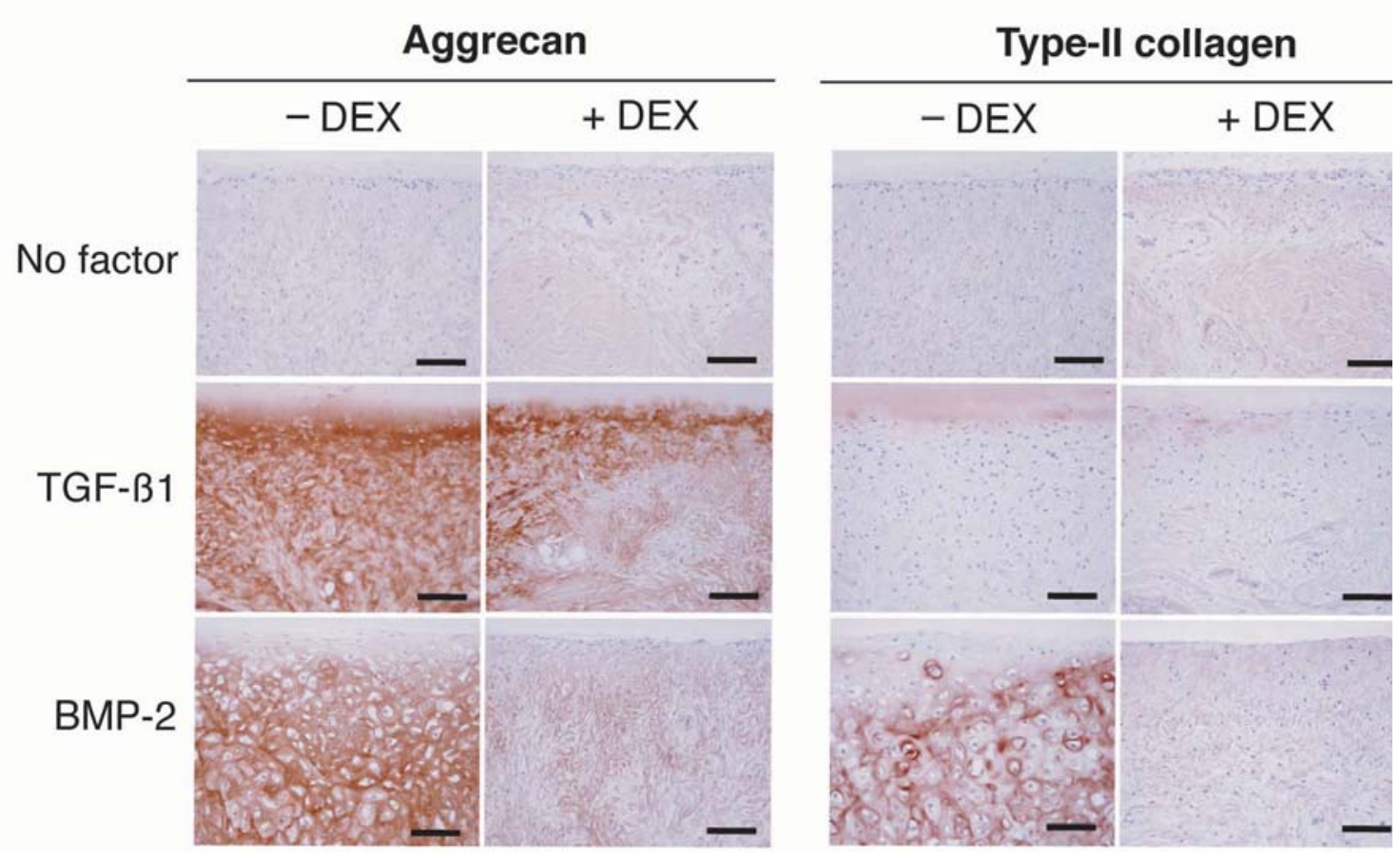

Fig. 1. DEX inhibits the TGF- $\beta 1$ - and BMP-2-induced deposition of GAGs $(\mathbf{A}, \mathbf{B})$ and type-II collagen $(\mathbf{B})$ in synovial explants - to a greater extent using the latter stimulant than the former. Synovial explants were cultured for 2 weeks (left sextet in A) or 4 weeks (right sextet in A, left and right sextets in $\mathbf{A}$ and $\mathbf{B}$ ) in the absence or presence of TGF- $\beta 1$, BMP-2 and DEX. (A) Light micrographs of Toluidine-Blue-stained sections. (B) Light micrographs of sections that had been immunostained for the detection of aggrecan or type-II collagen. The cell nuclei were counterstained with hematoxylin. The inset in A (right sextet: left-hand image in the bottom row) illustrates a higher-magnification view of the pericellular lacuna ("empty" space) that surrounds all chondrocytes as a result of their shrinkage during chemical processing in aqueous media. Bars: $100 \mu \mathrm{m}$. 


\section{Synovial Explants}

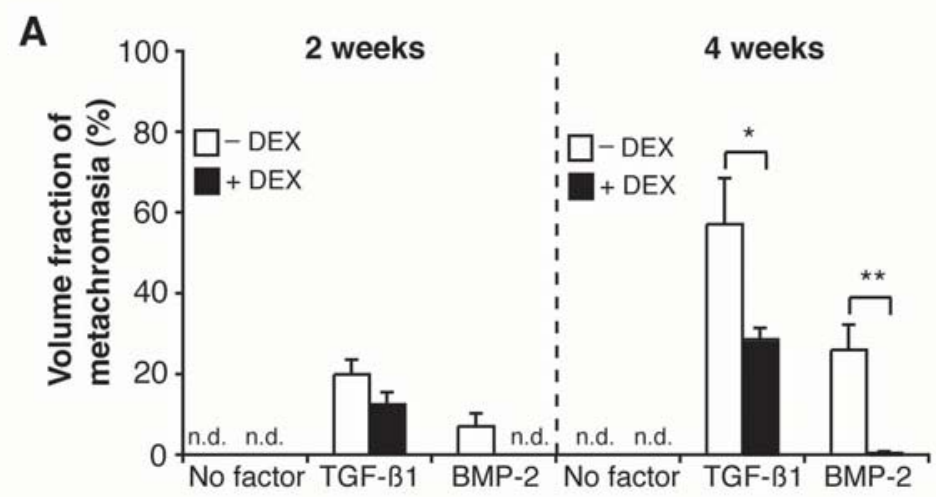

B

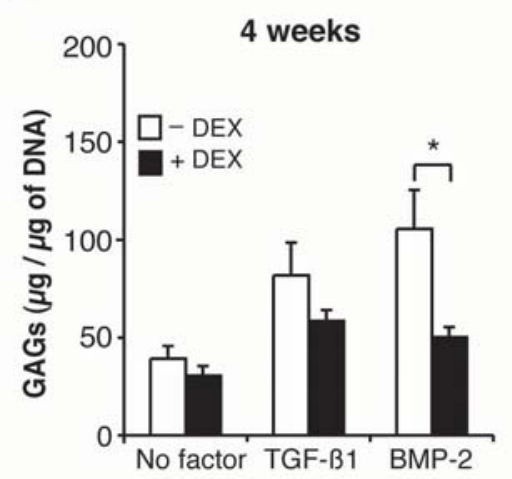

C

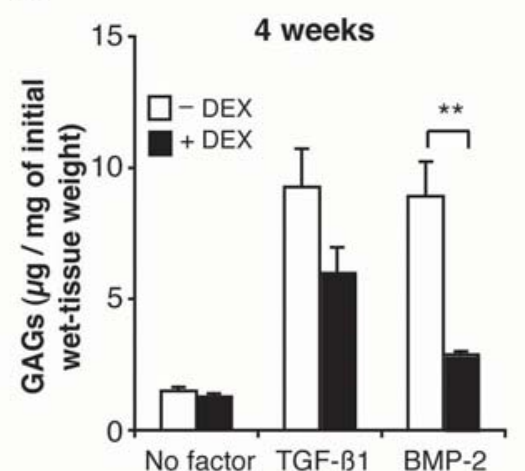

D

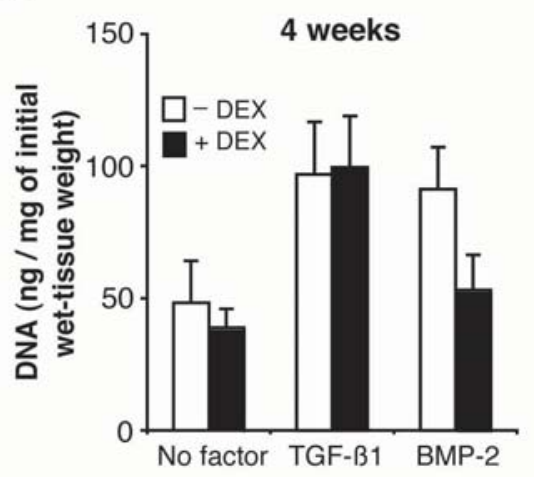

Fig. 2. DEX inhibits the TGF- $\beta 1$ - and BMP-2-induced accumulation of GAGs in synovial explants - to a greater degree in the latter case than in the former. Synovial explants were cultured for 2 or 4 weeks in the absence or presence of TGF- $\beta 1$, BMP-2 and DEX. (A) Volume fraction of metachromasia in synovial explants after culturing for 2 (left) or 4 weeks (right). (B, C) Glycosaminoglycan-content (GAGs) of synovial explants after 4 weeks of culturing. The GAG-content was expressed in $\mu \mathrm{g}$ per $\mu \mathrm{g}$ of DNA (B) and per mg of the initial wet explant weight (C). (D) DNAcontent of synovial explants (expressed in ng per $\mathrm{mg}$ of the initial wet explant weight) after 4 weeks of culturing. Mean values are represented together with the SEM $(n=4)$. *: $p<0.05$; **: $p<0.01$; n.d.: not detectable.

When DEX was included in the culture medium, BMP-2 failed to induce either metachromasia (Fig. 1A) or cell differentiation (Fig. 1 A,B).

Immunohistochemistry for aggrecan and type-II collagen was also performed. In the absence of a growth factor, neither aggrecan nor type-II collagen was detected in synovial explants, irrespective of the absence or presence of DEX (Fig. 1B). After stimulation with TGF- $\beta 1$ in the absence of DEX, immunostaining for aggrecan was intense in synovial explants (Fig. 1B). DEX suppressed the TGF$\beta 1$-stimulated deposition of aggrecan in synovial explants. Stimulation with TGF- $\beta 1$ in the absence of DEX led to weak immunostaining for type-II collagen in peripheral portions of the synovial explants. DEX suppressed the TGF- $\beta 1$-stimulated deposition of type-II collagen in synovial explants. After stimulation with BMP-2 in the absence of DEX, aggrecan and type-II collagen were deposited in synovial explants (Fig. 1B). DEX suppressed the BMP-2-stimulated deposition of these proteins (Fig. 1B).
The GAG-content of synovial explants was quantified histochemically by measuring the volume fraction of metachromasia and biochemically (in tissue digests) using the dimethylmethylene-Blue assay. After 4 weeks of culturing, the TGF- $\beta 1$-induced volume fraction of metachromasia was higher in the absence than in the presence of DEX (Fig. 2A); the GAG-contents per $\mu \mathrm{g}$ of DNA and per mg of the initial wet explant weight were also higher, but not significantly so (Fig. 2B,C). Likewise after 4 weeks of culturing, the BMP-2-induced volume fraction of metachromasia (Fig. 2A) and the GAG-content (Fig. 2B,C) were both significantly higher in the absence than in the presence of DEX. To assess the effect of DEX on cell number, the weight of DNA (measured at the end of the culturing period) was expressed per mg of the initial wet explant weight (Fig. 2D). After stimulation for 4 weeks with either TGF- $\beta 1$ or BMP-2, the DNA-content per mg of the initial wet explant weight was not significantly influenced by the absence or presence of DEX. 
A Synovial MSCs
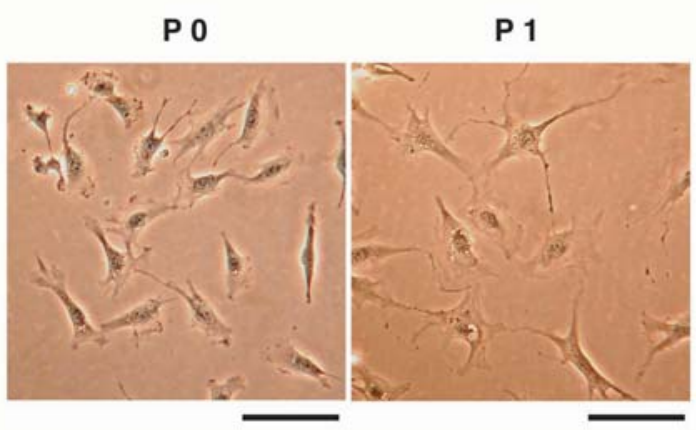

B

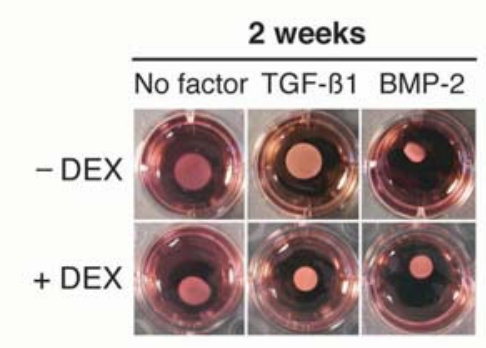

Synovial MSCs

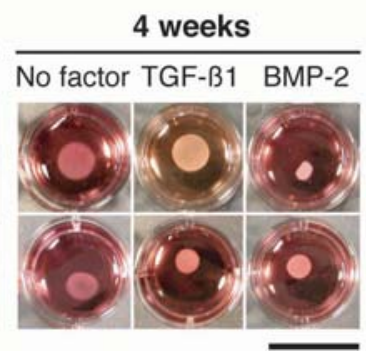

Bone-marrow-derived MSCs

P 0

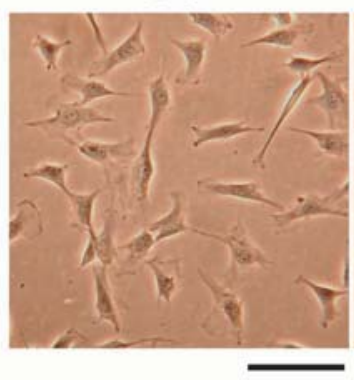

P 1

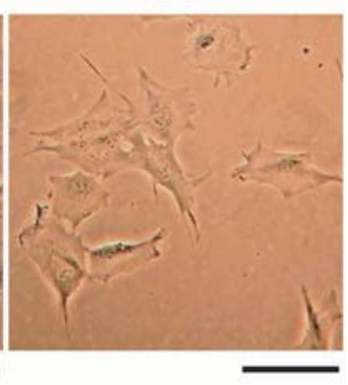

Bone-marrow-derived MSCs

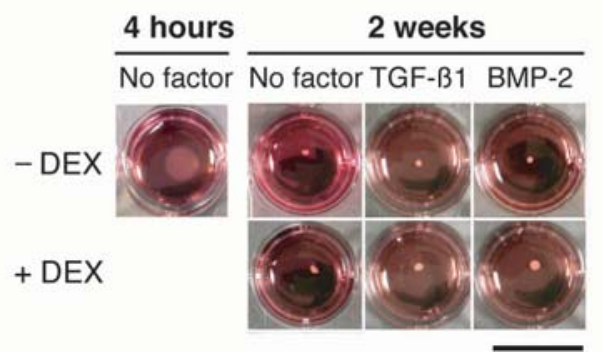

Fig. 3. Appearance of synovial and bone-marrow-derived MSCs. (A) Phase-contrast images of synovial (left pair) and bone-marrow-derived MSCs (right pair) prior to (P0) and during (P1) the first passage. Bars: $100 \mu \mathrm{m}$. (B) Appearance of aggregates of synovial MSCs (left) and of bone-marrow-derived MSCs (right). Aggregates were formed by incubating suspensions of MSCs for $4 \mathrm{~h}$ in 12-well plates. They were then cultured for 2 weeks (synovial and bone-marrow-derived MSCs) or 4 weeks (synovial MSCs) in the absence or presence of TGF- $\beta 1$, BMP-2 and DEX. Bars: $20 \mathrm{~mm}$.

\section{DEX significantly enhances the TGF-ß1-induced deposition of a cartilage-like matrix in MSC- aggregates of bone-marrow origin but not in those of synovial origin}

DEX promotes the TGF- $\beta 1$-induced chondrogenesis of aggregates of bone-marrow-derived MSCs (Johnstone et al., 1998; Yoo et al., 1998), but suppresses the TGF- $\beta 1$ induced accumulation of GAGs in synovial explants (as described above). This seemingly paradoxical response to DEX using the same growth factor could be attributable to a difference in either the microenvironment of the MSCs or their tissue origin. To clarify this issue, bone-marrowderived and synovial MSCs were cultured under the same high-density conditions as aggregates. Initially, the isolated MSCs were grown as monolayers in serum-containing medium (passage 0). Under these culturing conditions, both the synovial and the bone-marrow-derived MSCs had a fibroblast-like appearance and protruded irregularly branched cytoplasmic processes (Fig. 3A). After the first passage, the synovial MSCs had a similar shape but were somewhat larger; the bone-marrow-derived MSCs were much broader and the cytoplasmic processes had undergone considerable retraction (Fig. 3A).

The first-passage MSCs were plated as aggregates. Under these micromass-culturing conditions, the synovial and bone-marrow-derived MSCs behaved differently.
The aggregates of synovial MSCs formed disc-like units which maintained their shape during the entire 4-week culturing period (although discs cultured with a growth factor occasionally detached from the plates and shrank a little) (Fig. 3B: left). On the other hand, aggregates of bone-marrow-derived MSCs detached from the plates within a few days of culturing and formed spherical units, irrespective of the absence or presence of DEX (Fig. 3B: right). However, in the absence of DEX, the aggregates of bone-marrow-derived MSCs shrank so considerably during the course of time as to render necessary a termination of the culturing period after 2 weeks for the purpose of quantitative analysis.

In the absence of a growth factor, synovial MSCaggregates manifested no metachromasia after 4 weeks of culturing, irrespective of the absence or presence of DEX (Fig. 4A). In the absence of DEX, both TGF- $\beta 1$ and BMP-2 induced limited metachromatic staining of the ECM after 2 weeks of culturing, and the response was heightened after 4 weeks in both cases (Fig. 4A). Metachromatic staining was not significantly enhanced in the presence of DEX (Fig. 4A). In the absence of a growth factor, bone-marrow-derived MSC-aggregates manifested weak metachromatic staining of the ECM after 2 weeks of culturing, irrespective of the absence or presence of DEX (Fig. 4A). In the absence of DEX, neither TGF-B1 nor 
A Toluidine-Blue staining (metachromasia)

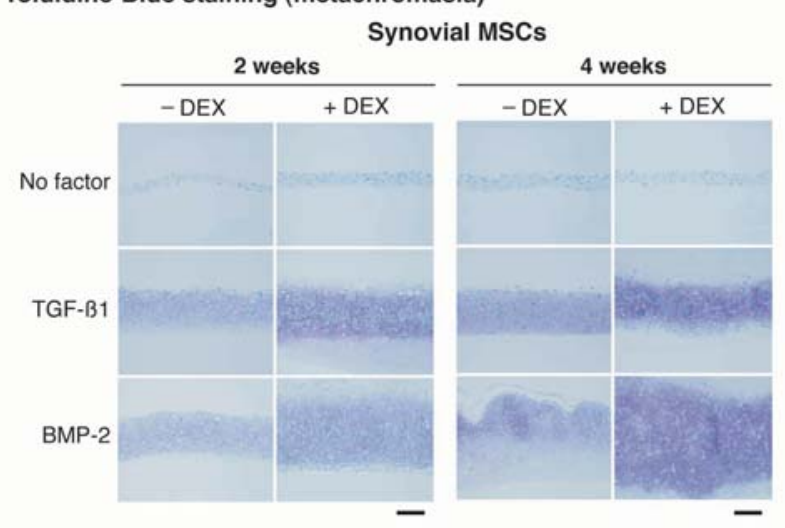

B Immunohistochemistry

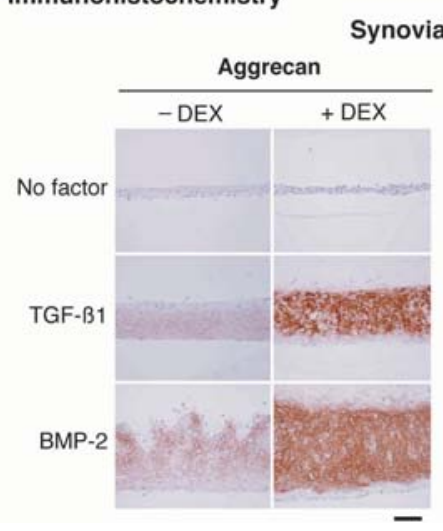

Synovial MSCs

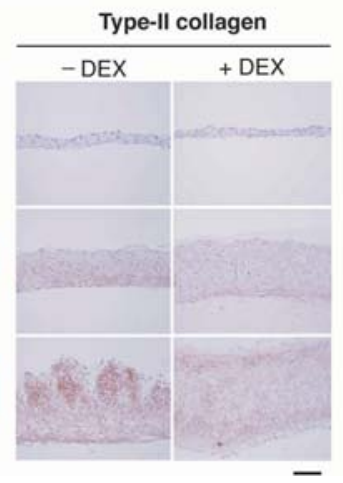

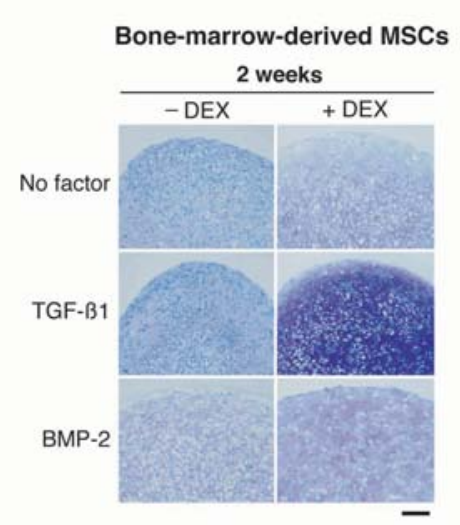

Fig. 4. DEX greatly enhances the TGF-ß1-induced deposition of GAGs (A, B) and type-II collagen (B) in aggregates of bone-marrow-derived MSCs but not in aggregates of synovial MSCs. (A) Light micrographs of Toluidine-Blue stained vertical sections through aggregates of synovial and bone-marrow-derived MSCs after culturing for 2 or 4 weeks (as indicated) in the absence or presence of TGF- $\beta 1$, BMP-2 and DEX. (B) Light micrographs of vertical sections through aggregates of synovial and bone-marrow-derived MSCs that had been cultured for 2 weeks (bonemarrow-derived MSCs) or 4 weeks (synovial MSCs) in the absence or presence of TGF- $\beta 1$, BMP-2 and DEX and then immunostained for the detection of aggrecan or type-II collagen. Cell nuclei were counterstained with hematoxylin. Bars: $100 \mu \mathrm{m}$.

BMP-2 enhanced this response. In the presence of DEX, TGF- $\beta 1$ induced a substantial increase in the intensity of metachromatic staining, whereas BMP-2 elicited a minimal one (Fig. 4A).

Immunohistochemistry for aggrecan and type-II collagen was performed on aggregates of isolated synovial MSCs that had been cultured for 4 weeks and on aggregates of bone-marrow-derived MSCs that had been cultured for 2 weeks. In the absence of a growth factor, aggregates of synovial MSCs manifested no immunoreactivity for either aggrecan or type-II collagen, irrespective of the absence or presence of DEX (Fig. 4B: left, top row). After stimulation with TGF- $\beta 1$ in the absence of DEX, aggregates of synovial MSCs manifested moderate immunostaining for aggrecan and weak immunoreactivity for type-II collagen (Fig. 4B: left, middle row). DEX enhanced the TGF- $\beta 1$ stimulated deposition of aggrecan but not that of type-II collagen. After stimulation with BMP-2 in the absence of DEX, aggregates of synovial MSCs manifested moderate immunoreactivity for both aggrecan and type-II collagen (Fig. 4B: left, bottom row). DEX enhanced the BMP-2- stimulated deposition of aggrecan but not that of type-II collagen.

In the absence of a growth factor and DEX, aggregates of bone-marrow-derived MSCs manifested very weak immunostaining for aggrecan but none for type-II collagen (Fig. 4B: right, top row). DEX enhanced the deposition of aggrecan but did not lead to the accumulation of type-II collagen. After stimulation with TGF- $\beta 1$ in the absence of DEX, aggregates of bone-marrow-derived MSCs manifested very weak immunoreactivity for aggrecan and almost none for type-II collagen (Fig. 4B: right, middle row). DEX enhanced the TGF-ß1-stimulated deposition of both aggrecan and type-II collagen. After stimulation with BMP-2 in the absence of DEX, aggregates of bone-marrow-derived MSCs manifested moderate immunoreactivity for aggrecan but almost none for typeII collagen (Fig. 4B: right, bottom row). DEX enhanced the BMP-2-stimulated deposition of both aggrecan and type-II collagen. We also quantified the GAG-content of MSC-aggregates biochemically. In aggregates of isolated synovial MSCs, DEX failed to enhance the GAG-content 


\section{A Synovial MSCs}

$$
\text { a }
$$

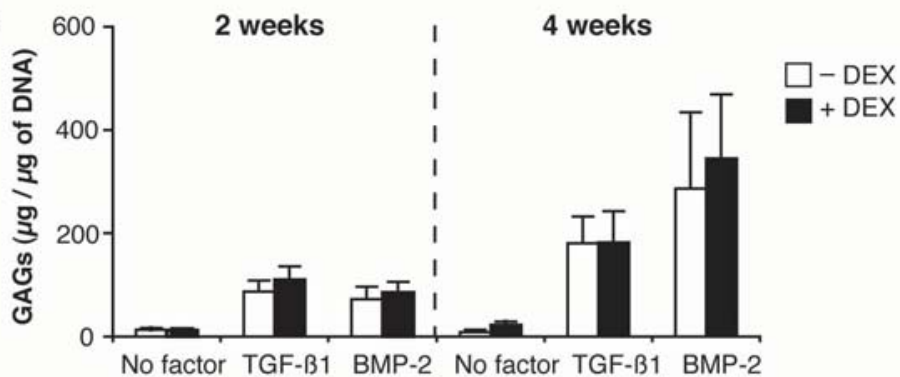

b

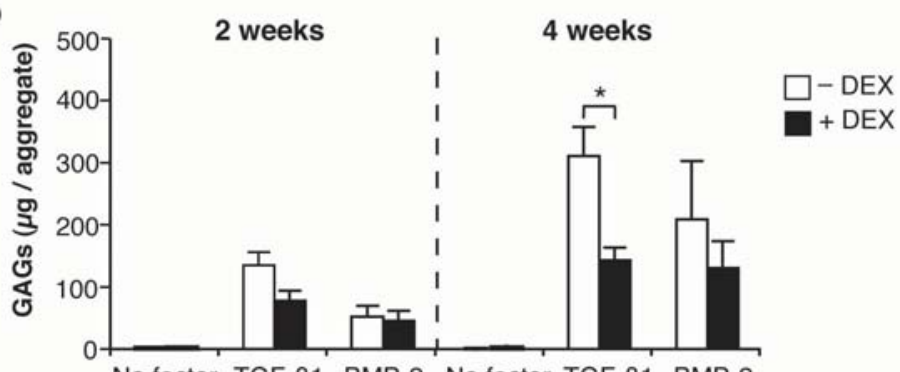

c

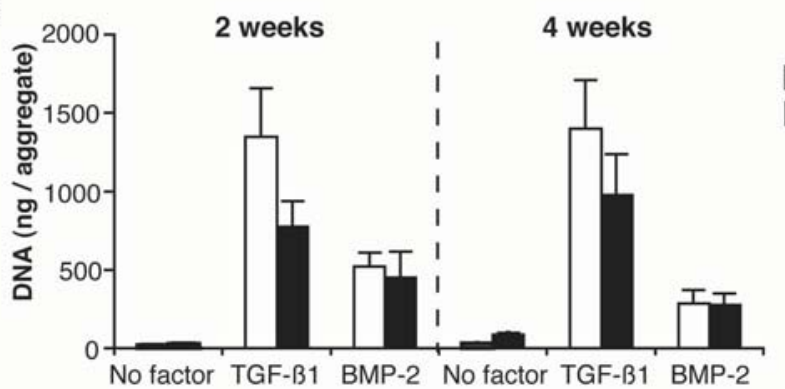

\section{B Bone-marrow-derived MSCs}

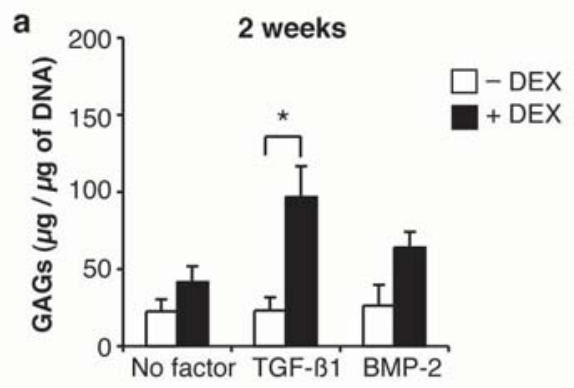

b
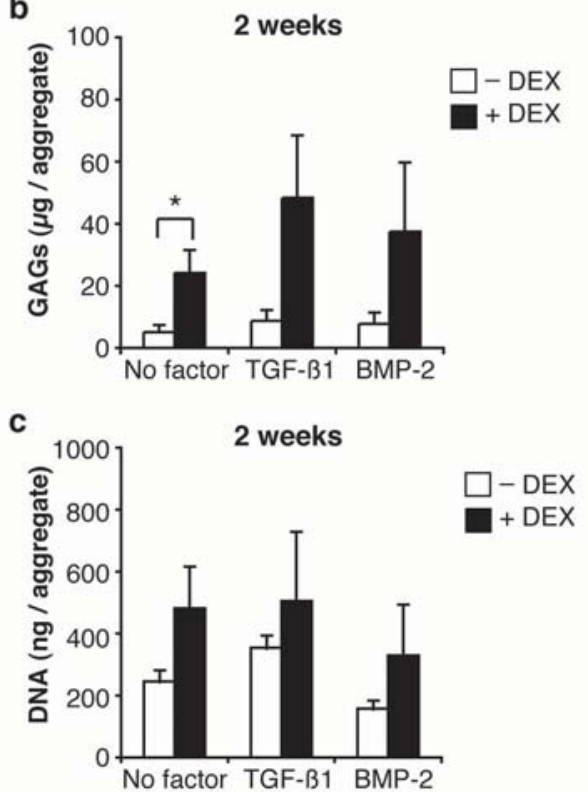

Fig. 5. DEX enhances the TGF- $\beta 1$-induced accumulation of GAGs in aggregates of bone-marrow-derived MSCs but not in aggregates of synovial MSCs. Aggregates of synovial MSCs (A) were cultured for 2 or 4 weeks, and those of bone-marrow-derived MSCs for 2 weeks (B), in the absence or presence of TGF- $\beta 1$, BMP- 2 and DEX. (A:a, B:a) GAG-content per $\mu$ g of DNA. (A:b, B:b) GAG-content per aggregate. (A:c, B:c) DNA-content per aggregate. Mean values are represented together with the SEM $(n=4){ }^{*}: p<0.05$.

per $\mu \mathrm{g}$ of DNA, irrespective of the absence or presence of a growth factor (Fig. 5A:a). However, it significantly decreased the GAG-content per aggregate after stimulation with TGF- $\beta 1$ for 4 weeks (Fig. 5A:b). The latter effect was attributable to a decrease in the total amount of DNA per aggregate (Fig. 5A:c). In aggregates of bone-marrowderived MSCs that had been stimulated with TGF- $\beta 1$ for 2 weeks, DEX tended to enhance the GAG-content, both per $\mu$ g of DNA (significantly) (Fig. 5B:a) and per aggregate (not significantly) (Fig. 5B:b). The total amount of DNA per aggregate of bone-marrow-derived MSCs was not significantly influenced by the absence or presence of DEX (Fig. 5B:c).

DEX suppresses the expression of a panel of cartilaginous genes in synovial explants but not in aggregates of isolated synovial MSCs

To improve our understanding of the effects of DEX on the chondrogenic differentiation of synovial MSCs, we monitored the expression levels of a panel of cartilaginous genes in synovial explants and aggregates of isolated synovial MSCs after stimulation with either TGF- $\beta 1$ or BMP-2 for 2 or 4 weeks (Fig. 6A,B). In synovial explants that had been incubated in the absence of DEX, stimulation with TGF- $\beta 1$ led to significant increases in the geneexpression levels of type-XI collagen, aggrecan, COMP, Sox 9 and link protein after 2 weeks of culturing, and to further increases after 4 weeks. In aggregates of isolated synovial MSCs, stimulation with TGF- $\beta 1$ led to increases in the expression levels of the same genes after 2 weeks of culturing; by the $4^{\text {th }}$ week, the expression levels had either decreased or plateaued.

In synovial explants that had been incubated in the absence of DEX, stimulation with BMP-2 led to significant increases in the gene-expression levels of collagen types II and IX, aggrecan, Sox 9 and link protein after 2 weeks of culturing, and to further increases after 4 weeks (Fig. 6A,B). In aggregates of isolated synovial MSCs, stimulation with BMP-2 led to increases in the expression levels of the same genes after 2 weeks of culturing; after 
A 2 weeks

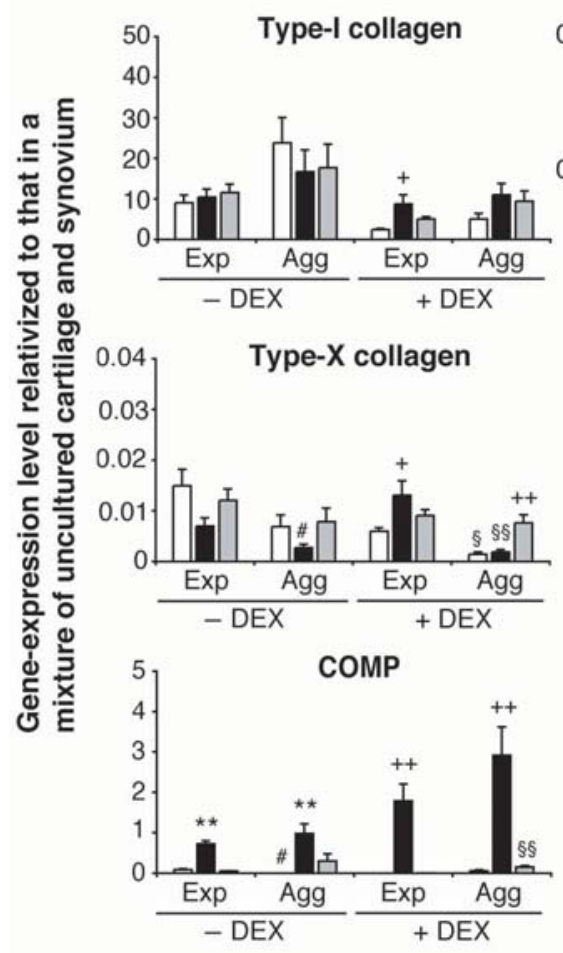

B 4 weeks

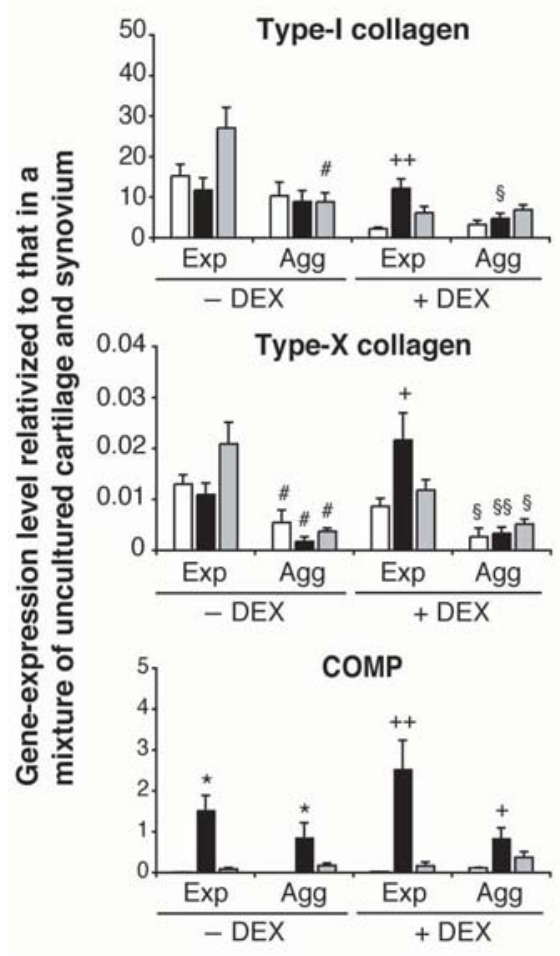

No factor

TGF-B1

BMP-2
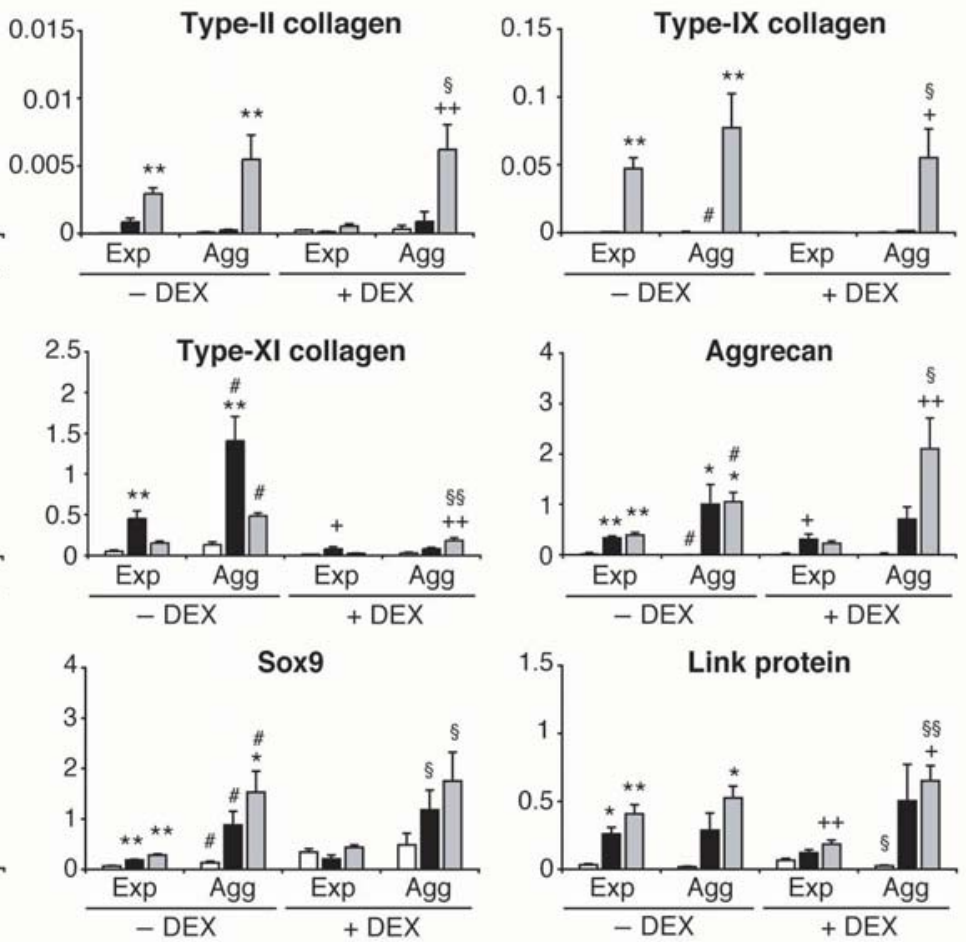

No factor $\square$ TGF-B1 $\square$ BMP-2
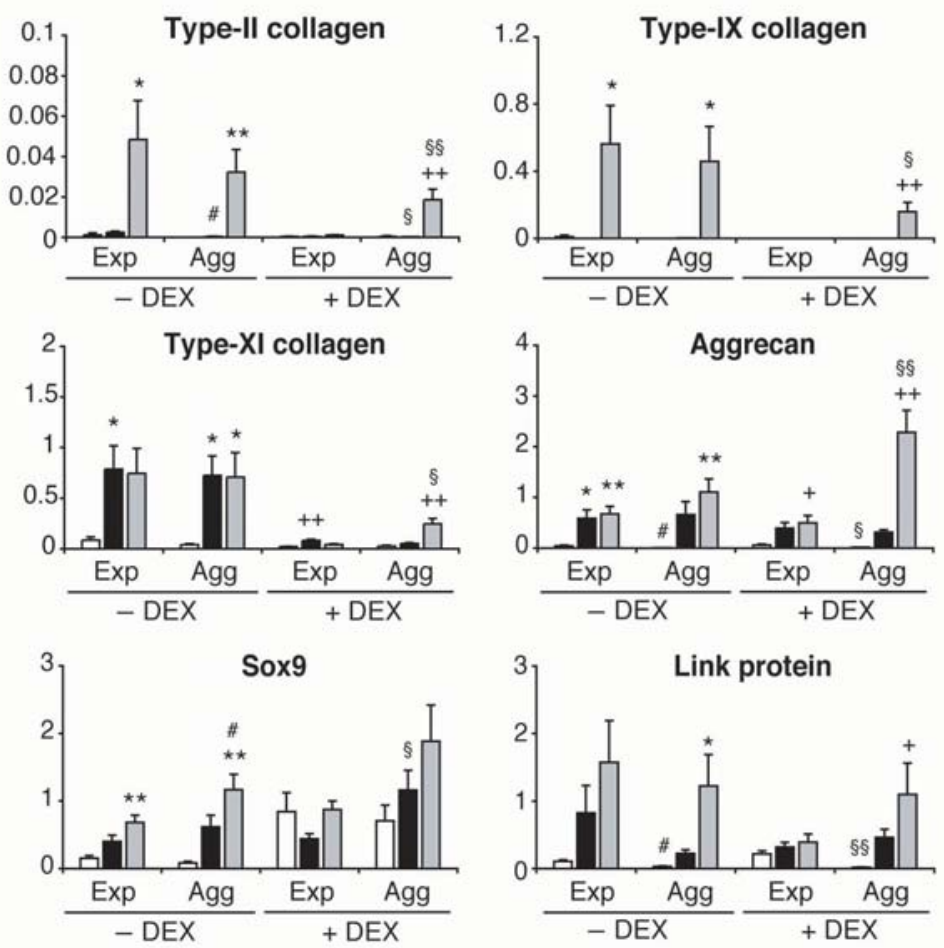

Fig. 6. Comparative expression profiles of the indicated genes in synovial explants (Exp) and in aggregates of isolated synovial MSCs (Agg), which had been cultured for 2 (A) or 4 weeks (B) in the absence or presence of TGF- $ß 1$, BMP2 and DEX. The expression level of each gene (determined by a quantitative real-time PCR analysis) was related to that in a calibrator (a mixture of uncultured cartilage and synovium) after normalization to that of $18 \mathrm{~S}$ rRNA. Mean values are represented together with the SEM $(n=5) .{ }^{*}: p<0.05$ vs. "no factor" in the absence of DEX; **: $p<0.01$ vs. "no factor" in the absence of DEX; $+: p<0.05$ vs. "no factor" in the presence of DEX; $++: p<0.01$ vs. "no factor" in the presence of DEX; \#: $p<0.05$ vs. each condition for Exp in the absence of DEX; $§: p<0.05$ vs. each condition for Exp in the presence of DEX; $\S \S: p<0.01 v s$. each condition for Exp in the presence of DEX. 

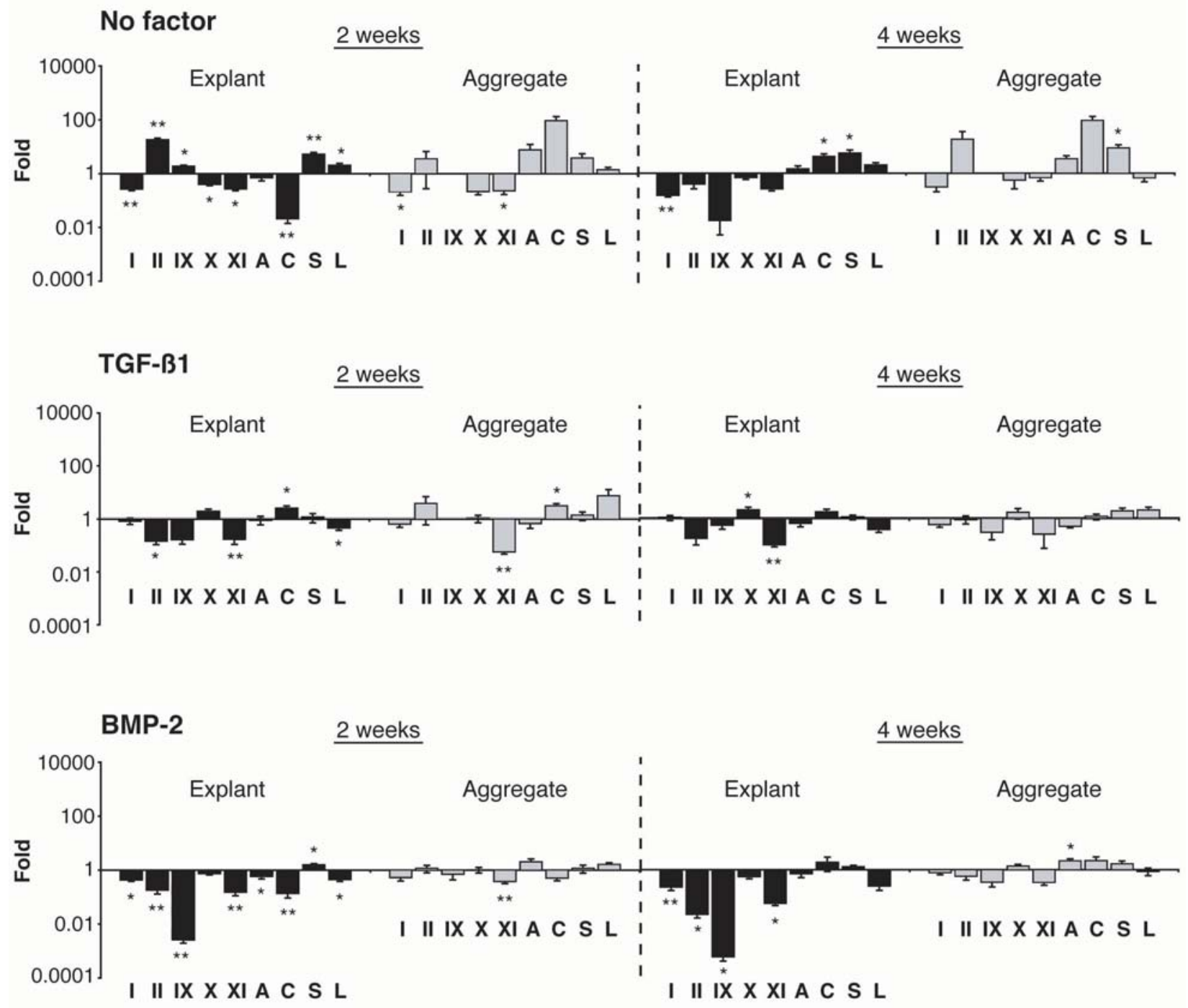

Fig. 7. Effects of DEX on the up- and down-regulation of the indicated genes in synovial explants and in aggregates of isolated synovial MSCs after 2 (left) or 4 weeks (right) of culturing in the absence or presence of TGF- $\beta 1$ and BMP-2. The gene-expression levels presented in Fig. 6 are here represented as ratios of the values in the presence to those in the absence of DEX. Mean values are represented together with the $\operatorname{SEM}(n=5) .^{*}: p<0.05 ; * *: p<0.01$. I: type-I collagen; II: type-II collagen; IX: type-IX collagen; X: type-X collagen; XI: type-XI collagen; A: aggrecan; C: COMP; S: Sox9; L: link protein.

4 weeks, the levels of collagen types II and IX and link protein had increased further.

In synovial explants that had been incubated in the presence of DEX, stimulation with TGF- $\beta 1$ led to significant increases in the gene-expression levels of collagen types I, X and XI, aggrecan and COMP after 2 weeks of culturing. After 4 weeks, further increases in the expression levels of all of these genes except type-XI collagen (no change) were manifested. In aggregates of isolated synovial MSCs, stimulation with TGF- $\beta 1$ evoked a significant increase in the gene-expression level of COMP alone; by the $4^{\text {th }}$ week, the level had decreased.

In synovial explants that had been incubated in the presence of DEX, stimulation with BMP-2 led to significant increases in the gene-expression levels of link protein (after 2 weeks) and aggrecan (after 4 weeks). In aggregates of isolated synovial MSCs, stimulation with
BMP-2 led to significant increases in the gene-expression levels of collagen types II, IX, X and XI, aggrecan and link protein after 2 weeks of culturing. After 4 weeks, the gene-expression levels of collagen types II, IX and XI and link protein had increased further.

We also compared the gene expression levels in the synovial explants with those in the aggregates of synovial MSCs (Fig. 6). In the absence of a growth factor and DEX, the gene expression levels of type-X collagen (4 weeks), aggrecan (2 and 4 weeks), COMP (2 weeks) and link protein (4 weeks) were significantly lower, and that of Sox9 (2 weeks) was significantly higher in aggregates than in explants. After stimulation with TGF- $\beta 1$ in the absence of DEX, the gene-expression levels of collagen types II (4 weeks), IX (2 weeks) and X (2 and 4 weeks) were significantly lower, and those of type-XI collagen ( 2 weeks) and Sox9 (2 weeks) significantly higher in aggregates 


\section{Bone-marrow-derived MSCs}

A No factor $\square$ TGF-B1 $\square$ BMP-2
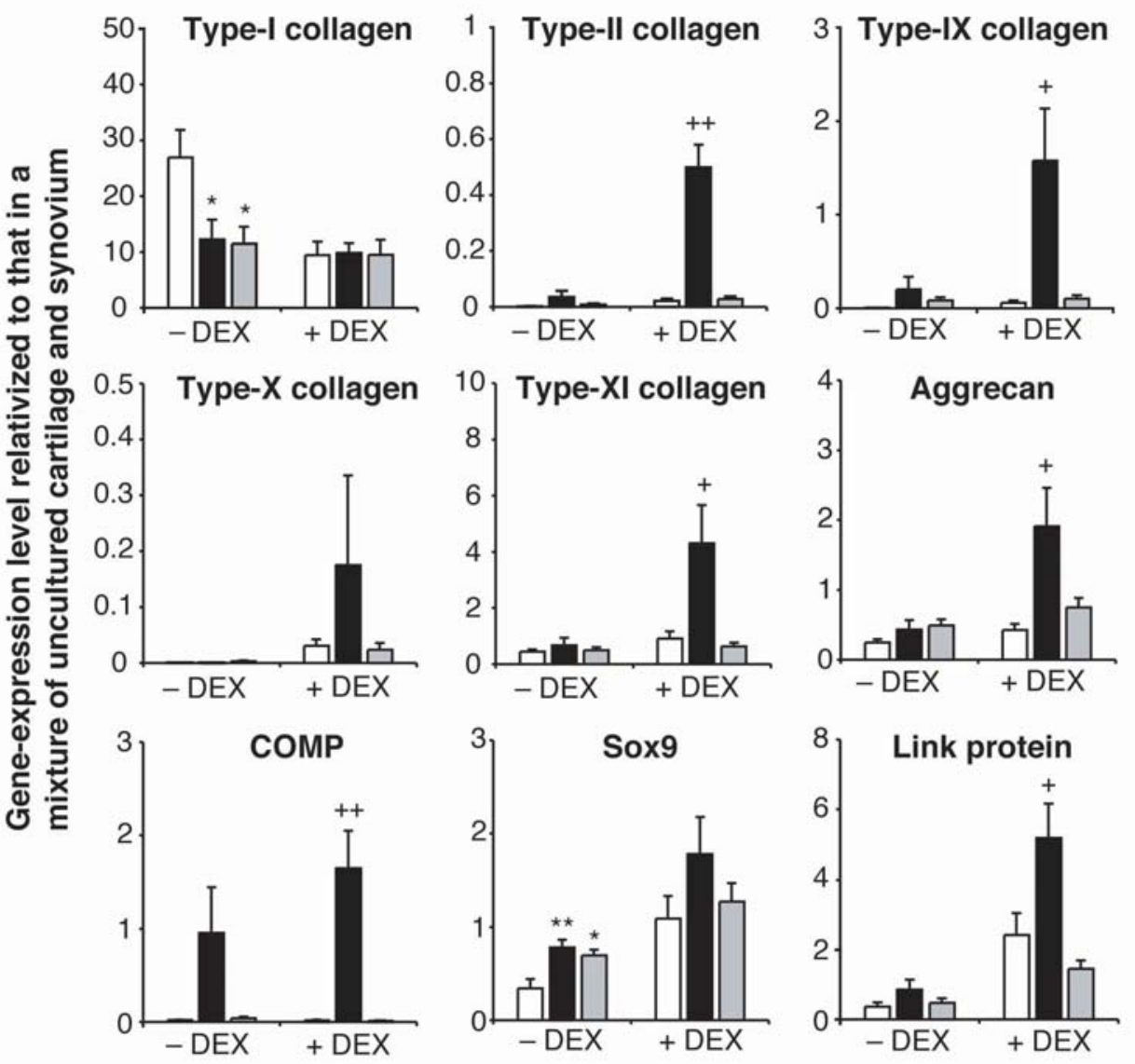

B
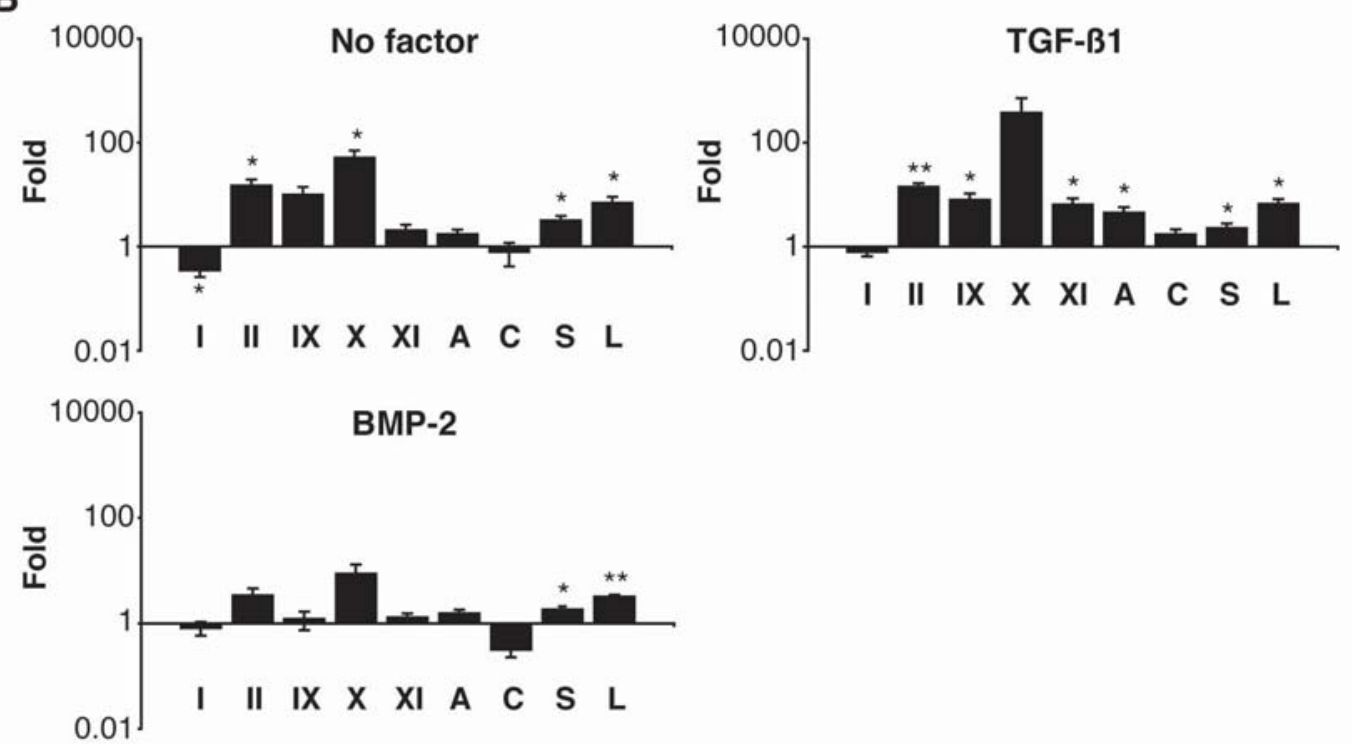

Fig. 8. Expression profiles of the indicated genes in aggregates of bone-marrow-derived MSCs after 2 weeks of culturing in the absence or presence of TGF- $\beta 1$, BMP-2 and DEX. (A) The expression level of each gene (determined by a quantitative real-time PCR analysis) was relativized to that in a calibrator (a mixture of uncultured cartilage and synovium) after normalization to that of $18 \mathrm{~S}$ rRNA. Mean values are represented together with the SEM $(n=5)$. *: $p<0.05$ vs. "no factor" in the absence of DEX; **: $p<0.01$ vs. "no factor" in the absence of DEX; +: $p<0.05$ vs. "no factor" in the presence of DEX; ++: $p<0.01$ vs. "no factor" in the presence of DEX. (B) The gene-expression levels in (A) are here represented as ratios of the values in the presence to those in the absence of DEX. Mean values are represented together with the $\operatorname{SEM}(n=5) . *: p<0.05 ; * *: p<0.01$. I: type-I collagen, II: type-II collagen, IX: type-IX collagen, X: type-X collagen; XI: type-XI collagen; A: aggrecan; C: COMP; S: Sox9; L: link protein. 
than in explants. After stimulation with BMP-2 in the absence of DEX, the gene-expression levels of collagen types I (4 weeks) and X (4 weeks) were significantly lower, and those of type-XI collagen ( 2 weeks), aggrecan ( 2 weeks) and Sox9 (2 and 4 weeks) significantly higher in aggregates than in explants. In the absence of a growth factor and the presence of DEX, the gene-expression levels of type-X collagen ( 2 and 4 weeks), aggrecan ( 4 weeks) and link protein ( 2 and 4 weeks) were significantly lower in aggregates than in explants. After stimulation with TGF- $\beta 1$ in the presence of DEX, the gene-expression levels of collagen types I (4 weeks), II (4 weeks) and X (2 and 4 weeks) were significantly lower, and that of Sox 9 (2 and 4 weeks) was significantly higher in aggregates than in explants. After stimulation with BMP-2 in the presence of DEX, the gene-expression level of type-X collagen (4 weeks) was significantly lower, and those of collagen types II ( 2 and 4 weeks), IX ( 2 and 4 weeks) and XI ( 2 and 4 weeks), aggrecan ( 2 and 4 weeks), COMP (2 weeks), Sox 9 ( 2 weeks) and link protein ( 2 weeks) were significantly higher in aggregates than in explants.

To gain a clearer idea of the influence of DEX on the up- and down-regulation of each gene, the data in Fig. 6 were represented as ratios of the expression levels in the presence to those in the absence of DEX (Fig. 7). DEX significantly up- and down-regulated gene expression even in unstimulated synovial explants and aggregates of isolated synovial MSCs. In synovial explants, DEX regulated gene expression according to the nature of the growth factor. After stimulation with TGF- $\beta 1$, DEX significantly down-regulated the genes for collagen types II and XI and link protein after 2 weeks of culturing, and that for type-XI collagen after 4 weeks. However, it significantly up-regulated the gene for COMP after 2 weeks of culturing, and that for type-X collagen after 4 weeks. After stimulation with BMP-2, DEX significantly down-regulated the genes for collagen types I, II, IX and $\mathrm{XI}$, aggrecan, COMP and link protein after 2 weeks of culturing, and those for collagen types I, II, IX and XI after 4 weeks. Only the gene for Sox 9 was up-regulated (after 2 weeks of culturing). In aggregates of isolated synovial MSCs, DEX down-regulated the expression only of the type-XI-collagen gene, and irrespective of whether they had been stimulated with TGF- $\beta 1$ or BMP-2. It significantly up-regulated the gene for COMP only after stimulation with TGF- $\beta 1$ for 2 weeks, and that for aggrecan only after stimulation with BMP-2 for 4 weeks.

\section{DEX enhances the expression of a panel of cartilaginous genes in bone-marrow-derived MSCs only after stimulation with TGF-ß1; not after stimulation with BMP-2}

In the present section, we address the chondrogenic response of bone-marrow-derived MSC-aggregates to DEX, TGF- $\beta 1$ and BMP-2 at the gene-expression level. In the absence of DEX, TGF- $\beta 1$ and BMP-2 suppressed the expression of the type-I-collagen gene and enhanced that of the Sox9 gene (Fig. 8A). However, neither TGF- $\beta 1$ nor BMP-2 enhanced the expression of any of the genes that serve as markers for a cartilaginous ECM. In the presence of DEX, TGF- $\beta 1$ stimulated increases in the gene-expression levels of collagen types II, IX and XI, aggrecan, COMP and link protein; BMP-2 exerted no effect on the expression levels of these genes. In Fig. $8 \mathrm{~B}$, the data for each gene are represented as ratios of the expression levels in the presence to those in the absence of DEX. In unstimulated aggregates of bone-marrow-derived MSCs, DEX down-regulated the gene for type-I collagen and upregulated those for collagen types II and X, Sox 9 and link protein. After stimulation with TGF-ß1, DEX up-regulated the genes for collagen types II, IX and XI, aggrecan, Sox9 and link protein. After stimulation with BMP-2, DEX upregulated only the genes for Sox9 and link protein.

\section{Discussion}

Glucocorticoids are known to have variable effects on cell activities. They have been shown not only to inhibit the proliferation and differentiation of osteoblasts (Weinstein et al., 1998; Pereira et al., 2001), but also to promote the latter process, as well as to enhance alkaline-phosphatase activity and mineralization (Aubin, 1999; Jorgensen et al., 2004; Purpura et al., 2004). Likewise in the case of chondrocytes, glucocorticoids have been shown not only to promote the differentiation of these cells (Quarto et al., 1992) and their elaboration of a cartilaginous matrix (Kato and Gospodarowicz, 1985; Takano et al., 1985; Sekiya et al., 2001), but also to inhibit their growth and their expression of type-II collagen (Miyazaki et al., 2000). Published data are thus conflicting, and the actions of glucocorticoids are ill- defined. DEX, a synthetic glucocorticoid, is frequently used to promote the chondrogenesis of MSCs in vitro. However, it has not been hitherto recognized that the effects of DEX on this process are context dependent. In the present study, the effects of DEX on the chondrogenesis of MSCs were shown to depend upon their microenvironment, their tissue origin and the nature of the growth factor (TGF- $\beta 1$ or BMP-2).

\section{DEX suppresses the chondrogenic differentiation of MSCs in synovial explants to a degree that depends upon the nature of the growth factor}

Previously, we have shown that the BMP-2-induced metachromasia of bovine synovial explants occurred only when DEX was excluded from the culturing medium (Shintani and Hunziker, 2007). In the present study, we have demonstrated that DEX almost completely inhibits the BMP-2-induced chondrogenic differentiation of synovial explants as gauged by the volume fraction of metachromasia and the GAG-content. We have further shown that the effect of DEX is achieved via a down-regulation of the genes for collagen types I, II, IX and XI, COMP and link protein, as well as that for aggrecan (responsible for metachromasia). Not surprisingly therefore, dramatic decreases in the protein levels of type-II collagen and aggrecan were demonstrated immunohistochemically. Interestingly, in contrast to its effect on other marker genes for a cartilaginous matrix, DEX up-regulated the gene for Sox 9 - a transcription factor that is crucial for chondrogenesis (Akiyama, 2008) and particularly for the expression of the genes for collagen types II, IX and XI 
and aggrecan (Bi et al., 1999). Contradictory findings relating to the gene expression of type-II collagen and Sox 9 have been documented also by other investigators. Using chondrocytes that were derived from adult human articular cartilage, Aigner et al. demonstrated the absence of a correlation between the gene-expression levels of Sox 9 and type-II collagen, thereby indicating that the expression of the former gene does not alone suffice for that of the latter (Aigner et al., 2003). Our own data suggest that DEX may regulate the gene expression not only of typeII collagen but also that of collagen types IX and XI and aggrecan via a pathway involving other factors than Sox9.

Whilst DEX inhibits the BMP-2-induced chondrogenic differentiation of synovial explants, it promotes the TGF- $\beta$ induced chondrogenesis of bone-marrow-derived MSCs (Johnstone et al., 1998; Yoo et al., 1998; Derfoul et al., 2006). We thus wished to ascertain whether DEX likewise inhibits the TGF- $\beta 1$ induced chondrogenesis of synovial explants. Although TGF- $\beta 1$-induced the accumulation of GAGs in synovial explants that were cultured in the absence of DEX, type-II collagen was deposited in smaller quantities than after stimulation with BMP-2, as gauged immunohistochemically. But, unlike BMP-2, TGF- $\beta 1$ was still capable of inducing metachromasia of the ECM when DEX was present, albeit to a lower degree than when it was absent. Furthermore, DEX down-regulated fewer genes in synovial explants that had been stimulated with TGF- $\beta 1$ rather than with BMP-2. DEX thus suppresses both the TGF- $\beta 1$ - and BMP-2-induced chondrogenesis of MSCs in synovial explants, but to a lesser degree in the former case than in the latter.

\section{The effects of DEX on the chondrogenic differentiation of synovial MSCs are influenced by their microenvironment, whereas those of the growth factors are not}

To evaluate the influence of the microenvironment on the effects of DEX, we compared its action on the TGF- $\beta 1$ - and BMP-2-stimulated chondrogenic differentiation of synovial explants and aggregates of isolated synovial MSCs. In contrast to its inhibitory effect on the chondrogenic differentiation of synovial explants, DEX had no influence on either the TGF- $\beta 1$ - or BMP-2-induced metachromaticstaining properties of aggregates of isolated synovial MSCs, and it even enhanced immunostaining for aggrecan after exposure to these growth factors. Similarly, it did not decrease either the TGF- $\beta 1$ - or BMP-2-induced increase in GAG content per $\mu \mathrm{g}$ of DNA. However, it significantly decreased the TGF- $\beta 1$-induced increase in GAG-content per aggregate. We suspect that the latter finding reflects a loss of cells during culturing, since, after stimulation for 4 weeks with TGF- $\$ 1$, the amount of DNA per aggregate was lower in the presence than in the absence of DEX.

The effects of DEX on synovial explants and aggregates of isolated synovial MSCs also differed at the gene-expression level. In aggregates of isolated synovial MSCs, DEX significantly down-regulated only the typeXI-collagen gene after stimulation with TGF- $\beta 1$ or BMP- 2 . Under the influence of BMP-2, it up-regulated the aggrecan gene, which accords with the immunohistochemical finding. However, after stimulation with TGF- $\beta 1$, it failed to up-regulate the aggrecan gene, which is at variance with the immunohistochemical finding. Aggrecan is known to bind to other matrix proteins, such as cartilage matrix protein, link protein and COMP (Neame and Barry, 1993; Hauser et al., 1996; Chen et al., 2007). We thus speculate that a TGF- $\beta 1$-induced up-regulation of other genes may promote the deposition of aggrecan in aggregates of isolated synovial MSCs.

Our data afford evidence that the microenvironment of synovial MSCs influences their response to DEX. As yet, we cannot account for this finding. Conceivably, their isolation and expansion may impact their chondrogenic responsiveness. Under the same stimulation conditions, the expression levels of several genes (type-X collagen, aggrecan, COMP and link protein in the absence of a growth factor; collagen types II, IX, X and XI and Sox 9 after exposure to TGF- $\beta 1$; collagen types I, X and XI, aggrecan and Sox9 after exposure to BMP-2) differed significantly between synovial explants and aggregates of synovial MSCs (Fig. 6). For example, the gene-expression levels of Sox9 (2 weeks) were consistently higher in aggregates, whereas those of type-X collagen (4 weeks) were consistently higher in explants. However, in the absence of DEX, their chondrogenic responsiveness either to TGF- 31 or to BMP-2 did not differ: in both synovial explants and aggregates of synovial MSCs, the geneexpression levels of collagen types II, IX and X, Sox9 and link protein were consistently higher after stimulation with BMP-2 than after exposure to TGF- $\beta 1$, whereas those of COMP and type-XI collagen were consistently higher after stimulation with TGF- $\beta 1$ than after exposure to BMP-2 (Fig. 6). Only the responsiveness to DEX appears to be impacted by the microenvironment of the synovial MSCs. Furthermore, we have previously demonstrated that when isolated synovial MSCs are seeded at low numerical densities within a matrix (alginate), DEX completely suppresses their BMP-2-induced chondrogenesis (Park et al., 2005; Kurth et al., 2007), as it does the BMP2 -induced chondrogenesis of synovial explants. These findings indicate that it is indeed the microenvironment (including the numerical density of cells) that influences the responsiveness of synovial MSCs to DEX, and not the isolation and expansion procedures per se.

We suspect that the microenvironment influences the effect of DEX on the chondrogenesis not only of synovial but also of bone-marrow-derived MSCs. This tenet is supported by the findings of Buxton et al. (Buxton et al., 2011). These authors demonstrated that hydrogelcultured MSCs of bone-marrow origin could be induced to undergo chondrogenesis in the absence of DEX. A similar phenomenon has been reported for chondrocytes: whilst glucocorticoids promote the differentiation of isolated chondrocytes (Quarto et al., 1992) and stimulate their synthesis of proteoglycans (Kato and Gospodarowicz, 1985; Takano et al., 1985), they suppress the growth of cartilage explants, as well as their synthesis of proteoglycans and collagen (Barrett et al., 1966; Tessler and Salmon, 1975; Silbermann et al., 1987). 
The chondrogenic effects not only of DEX but also of growth factors are influenced by the tissue source of the MSCs

In aggregates of isolated synovial MSCs that were cultured without DEX, TGF- $\beta 1$ stimulated a considerable increase in the deposition of GAGs but only a barely detectable one in that of type-II collagen. DEX enhanced neither the accumulation of GAGs (although an increase in the aggrecan-content was demonstrated immunohistochemically) nor the deposition of type-II collagen. In other studies using bone-marrow-derived MSCs (Johnstone et al., 1998; Yoo et al., 1998; Derfoul et al., 2006), DEX enhanced the deposition of both GAGs and type-II collagen. To ascertain whether the responsiveness of MSCs to DEX is influenced by their tissue origin, bone-marrow-derived MSCs were cultured under the same conditions as isolated synovial MSCs, namely, as aggregates.

Consistent with existing data (Johnstone et al., 1998; Yoo et al., 1998; Derfoul et al., 2006), DEX greatly enhanced the TGF- $\beta 1$-induced chondrogenesis of aggregates of bovine bone-marrow-derived MSCs, as evidenced by the accumulation of GAGs (histochemical and biochemical determinations) and by the immunohistochemically demonstrated deposition of type-II collagen and aggrecan. DEX also up-regulated the genes for collagen types II, IX and XI, aggrecan and link protein. Hence, the effects of DEX on the TGF- $\beta 1$ induced chondrogenesis of MSCs are clearly influenced by their tissue source. Many researchers have shown BMPs to be capable of inducing the chondrogenesis of bone-marrow-derived MSCs (Majumdar et al., 2001; Schmitt et al., 2003; Sekiya et al., 2005; Neumann et al., 2007). In these previous studies, DEX was unquestioningly introduced into the culture medium, following the precedent for TGF- $\beta 1$ induced chondrogenesis. However, whether DEX is really necessary for the BMP-2-induced chondrogenesis of bone-marrow-derived MSCs has never been established. In the present study, DEX did indeed enhance the BMP-2induced chondrogenesis of bone-marrow-derived MSCs. However, its effect was much weaker under the influence of BMP-2 than under that of TGF- $\beta 1$.

Incidentally, the present study has revealed synovial and bone-marrow-derived MSCs to manifest different aggregation behaviors: synovial MSCs formed disc-like units, whereas bone-marrow-derived MSCs formed spherical ones, which were smaller (Fig. 3B) and contained lesser amounts of DNA and GAGs per aggregate (Fig. 5A:b,c and Fig. 5B:b,c). The bone-marrow-derived MSC-aggregates thus contained few surviving cells. After stimulation for 3 weeks with TGF- $\beta 3$ and BMP-2 in the presence of DEX, Sakaguchi et al. compared the chondrogenic potentials of pelleted synovial and bonemarrow-derived MSCs on the basis of their wet weights as well as their histology (Sakaguchi et al., 2005). In a later study, they also monitored the gene-expression levels of type-II collagen, as well as the amounts of chondroitin sulfate and hyaluronan per pellet (Yoshimura et al., 2007). Since the final wet weights of the pelleted synovial MSCs were found to be greater than those of the bone-marrow-derived ones in the earlier study (Sakaguchi et al., 2005), the authors concluded that the former had a higher chondrogenic potential per pellet than the latter. In a previous study of ours, the weights of synovial explants did indeed accord with the degree of chondrogenesis (Shintani and Hunziker, 2007). However, in the present study, aggregates of viable bone-marrow-derived MSCs that had been stimulated with TGF- $\beta 1$ in the presence of DEX deposited greater quantities of type-II collagen than did those of viable synovial MSCs that had been stimulated with BMP-2 in the absence of DEX (Fig. 4), even though aggregates of bone-marrow-derived MSCs were smaller than those of synovial MSCs (Fig. 3B). This finding indicates that when the MSCs are derived from different tissue sources, the size of an aggregate does not reflect the degree of chondrogenic differentiation per cell. This parameter will be influenced by the number of surviving cells, which could be tissue-source dependent. Whether this tenet holds true for pellet cultures (Sakaguchi et al., 2005), that is to say, for compacted masses of cells that are generated by centrifugation, is not known. But, at least for micromass cultures, that is to say, for high-density masses of cells that are formed from suspensions by spontaneous sedimentation under the force of gravity, a size (weight) comparison between MSC-aggregates from different tissue sources is not alone a reliable indicator of their relative chondrogenic potentials.

Not only DEX, but also the nature of the growth factor influences the chondrogenic differentiation of MSCs of diverse tissue origins. TGF- $\beta 1$ alone (without DEX) stimulated barely detectable increases in the GAG-content and expression levels of cartilaginous genes in aggregates of bone-marrow-derived MSCs, but substantial ones in aggregates of synovial MSCs. Likewise, BMP-2 alone failed to stimulate either the deposition of type-II collagen or the expression of cartilaginous genes to a significant degree in aggregates of bone-marrow-derived MSCs, but did so in aggregates of synovial MSCs.

\section{Putative mechanisms that might account for the wayward effects of DEX}

At present, we can offer no plausible explanation for the variable effects of DEX on the chondrogenic differentiation of MSCs. The physiological and pharmacological actions of glucocorticoids (including synthetic ones) are predominantly mediated via the ubiquitously-expressed glucocorticoid receptor (GR) (Chrousos and Kino, 2005). To date, two isotypes have been identified: GR $\alpha$ and GR $\beta$ (Bamberger et al., 1995). GRß is a dominant inhibitor of GR $\alpha$, and changes in the cellular GR $\alpha$-to-GR $\beta$ ratio can influence sensitization and resistance to glucocorticoids (Gross and Cidlowski, 2008). Human bone-marrowderived MSCs have been reported to express both GR $\alpha$ and GR $\beta$ (Derfoul et al., 2006). Furthermore, over expression of GRß has been shown to inhibit the DEXand TGF-ß- induced up-regulation of reporter activity for the type-II-collagen-gene promoter. We suspect that the distribution of GR-isoforms on MSCs may be influenced by their microenvironment and tissue origin, as well as by the nature of the growth factor to which they are exposed, and that these differences in GR-isoform topography may 

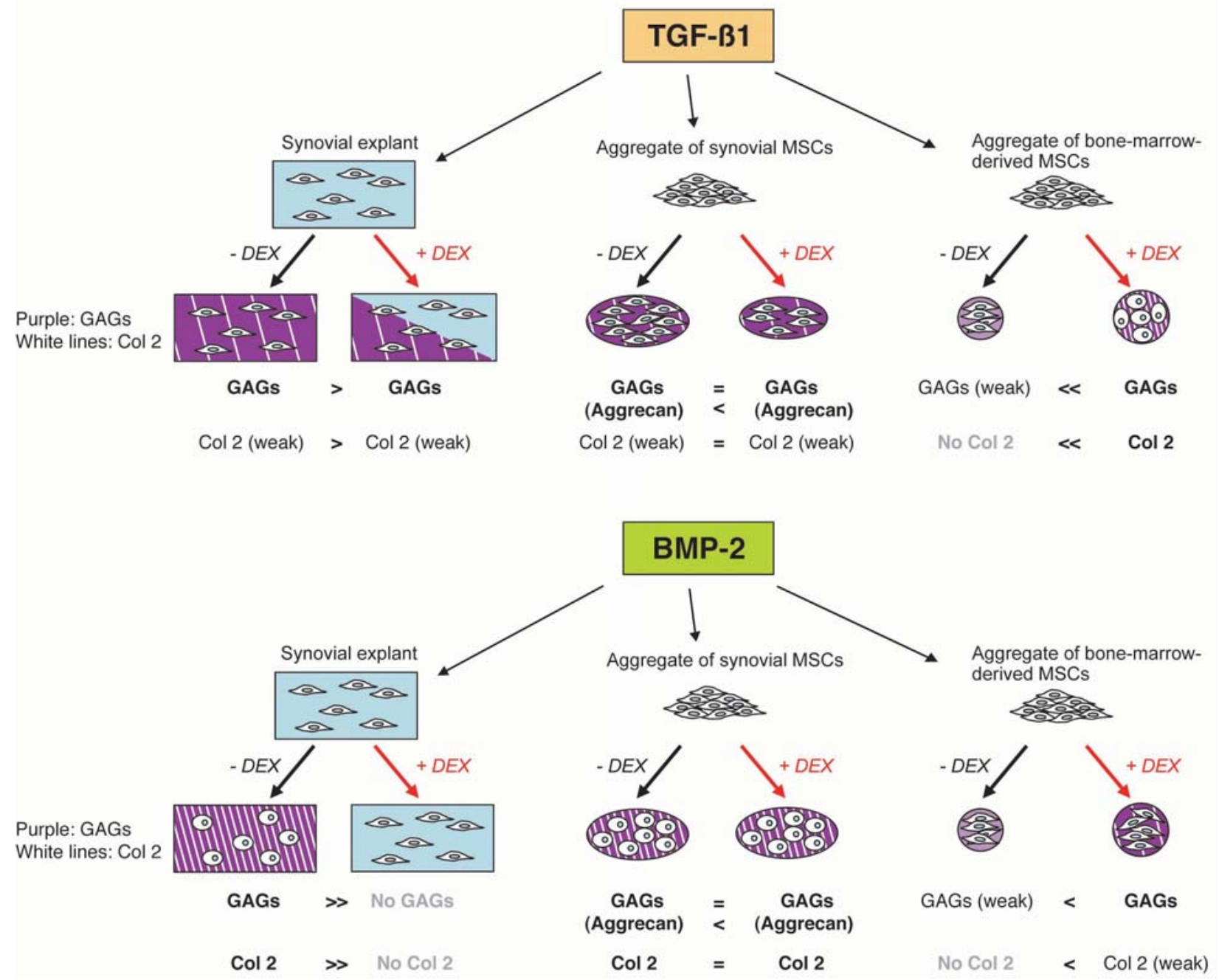

Fig. 9. Scheme summarizing the wayward effects of DEX on the TGF- $\beta$ - or BMP-2-induced chondrogenic differentiation of synovial explants, aggregates of synovial MSCs and aggregates of bone-marrow-derived MSCs. Relative differences in the GAG-content (histochemical and biochemical analyses), and in the deposited quantities of aggrecan and type-II collagen (Col2) (immunohistochemical analysis), are indicated as follows: "> ": higher on the left of the arrowhead; "<": higher on the right of the arrowhead; "=": equal; ">>": much higher on the left of the arrowhead; " <<": much higher on the right of the arrowheads.

partially account for the wayward effects of DEX on their chondrogenic differentiation.

The role played by the microenvironment in regulating the influence of DEX on chondrogenesis (perhaps by modulating the expression of the GRs) is as yet unknown. Components of the ECM not only afford structural support for the cells but also generate signals for the regulation of their adhesion, differentiation, spreading and migration (Hynes, 2009). ECM signals are transduced to the cell interior after binding to transmembrane receptors: the integrins (Hynes, 2002), which also function in cell-cell contacts and in cross talk with growth factors (Prowse et al., 2011). It is thus conceivable that integrin-mediated interactions with ECM components regulate the influence of DEX on the chondrogenic differentiation of MSCs. If so, then the response would be expected to vary according to the composition of the cellular microenvironment. The ECM also acts as a reservoir for growth factors (Hynes, 2009). It can bind and sequester these, possibly affecting their bioavailability and activity. ECM-bound growth factors can be differentially released to establish local concentration gradients, which may be important for patterning during embryonic development. We do not know whether DEX can likewise bind to components of the ECM, but the binding and sequestration of the growth factors could partially account for its different effects on the TGF- $\beta 1$ - and BMP-2-induced chondrogenesis of MSCs in synovial explants (presence of a natural ECM) and aggregates (absence of a natural ECM).

We cannot as yet explain how DEX differentially modulates the TGF- $\beta 1$ - and BMP-2-induced chondrogenesis of MSCs at the signal-transduction level. TGF- $\beta$ s and BMPs are members of the TGF- $\beta$ superfamily. They bind to specific type-II receptors on cell surfaces, thereby triggering the recruitment of type-I receptors and the cascade of events that lead to the phosphorylation of specific receptor-regulated Smads (R-Smads) (Miyazono et al., 2001). TGF-ß-signaling is mediated by Smads 2 and 3 , and BMP-signaling by Smads 1, 5 and 8 (Miyazono et al., 2001). The simultaneous deletion of Smads 1 and 
5 in mice leads to severe chondrodysplasia (Retting et al., 2009). This finding indicates that BMP-signaling is essential for chondrogenesis in vivo. On the other hand, deletion of Smad3 enhances the terminal differentiation of chondrocytes and leads to an osteoarthritic degeneration of articular cartilage (Yang et al., 2001). These findings reveal the importance of TGF- $\beta$-signaling in the regulation of terminal chondrocytic hypertrophy and in the maintenance of articular cartilage. However, TGF- $\beta$ does not appear to be essential for chondrogenesis per se. Mice in which the genes for TGF- $\beta 1$ and TGF- $\beta 3$, or that for TGF- $\beta 2$, have been deleted develop a normal skeleton; their limbs manifest only minor skeletal defects (Pryce et al., 2009; Sanford et al., 1997). Likewise in the present study, the chondrogenic potential of TGF- $\beta 1$ was lower than that of BMP-2 on the basis of the immunohistochemical findings, although the capacity of the two growth factors to stimulate the accumulation of GAGs (detected biochemically) did not differ significantly. In synovial explants and aggregates of synovial MSCs, BMP-2 stimulated a considerable increase in the deposition of type-II collagen, whereas TGF- $\beta 1$ elicited a barely detectable one, irrespective of the absence or presence of DEX. In bone-marrowderived MSCs that had been cultured in the absence of DEX, BMP-2 stimulated an increase in the deposition of aggrecan, whereas TGF- $\beta 1$ elicited a barely detectable

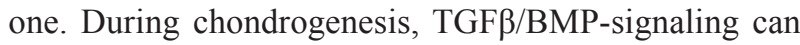
also be mediated via "redundant" regulatory pathways, which are controlled by mitogen-activated protein kinases (MAPKs) [such as p38, c-Jun $\mathrm{NH}_{2}$-terminal kinase (JNK) and extracellular signal regulated kinase (Erk)] (Miyazono et al., 2001). Miyazaki et al. have postulated that the inhibitory influence of DEX on the TGF- $\beta 1$-induced growth of rat articular chondrocytes, and their expression of the type-II-collagen gene, may be mediated by its suppression of the activity of the Erk-integrated activator protein-1 (AP-1) (Miyazaki et al., 2000). However, the molecular mechanisms that govern the influence of DEX on the TGF- $\beta 1$ - and BMP-2-induced chondrogenesis of MSCs are not precisely known and remain, as yet, a matter for speculation.

\section{Conclusions}

In the present study, we have demonstrated the effects of DEX on the chondrogenic differentiation of MSCs to be influenced by their microenvironment and tissue origin, as well as by the nature of the growth factor (Fig. 9). These findings have an important bearing on cartilageengineering approaches that draw on MSCs of different origins.

\section{Acknowledgements}

The authors are indebted to Simon Nüssli for his technical assistance. They would also like to thank Pfizer (formerly Wyeth) for providing them with a supply of recombinant BMP-2. This study was supported by an NIH grant [to EBH (no. 5 R01 AR052766)].

\section{References}

Aigner T, Gebhard PM, Schmid E, Bau B, Harley V, Poschl E (2003) Sox9 expression does not correlate with type II collagen expression in adult articular chondrocytes. Matrix Biol 22: 363-372.

Akiyama H (2008) Control of chondrogenesis by the transcription factor Sox9. Mod Rheumatol 18: 213-219.

Alsalameh S, Amin R, Gemba T, Lotz M (2004) Identification of mesenchymal progenitor cells in normal and osteoarthritic human articular cartilage. Arthritis Rheum 50: 1522-1532.

Aubin JE (1999) Osteoprogenitor cell frequency in rat bone marrow stromal populations: Role for heterotypic cell-cell interactions in osteoblast differentiation. J Cell Biochem 72: 396-410.

Bamberger CM, Bamberger AM, de Castro M, Chrousos GP (1995) Glucocorticoid receptor beta, a potential endogenous inhibitor of glucocorticoid action in humans. J Clin Invest 95: 2435-2441.

Barrett AJ, Sledge CB, Dingle JT (1966) Effect of cortisol on the synthesis of chondroitin sulphate by embryonic cartilage. Nature 211: 83-84.

Bi W, Deng JM, Zhang Z, Behringer RR, de Crombrugghe B (1999) Sox9 is required for cartilage formation. Nat Genet 22:85-89.

Buxton AN, Bahney CS, Yoo JU, Johnstone B (2011) Temporal exposure to chondrogenic factors modulates human mesenchymal stem cell chondrogenesis in hydrogels. Tissue Eng Part A 17: 371-380.

Chen FH, Herndon ME, Patel N, Hecht JT, Tuan RS, Lawler J (2007) Interaction of cartilage oligomeric matrix protein/thrombospondin 5 with aggrecan. J Biol Chem 282: 24591-24598.

Chrousos GP, Kino T (2005) Intracellular glucocorticoid signaling: A formerly simple system turns stochastic. Sci STKE 2005: pe48.

De Bari C, Dell'Accio F, Luyten FP (2001a) Human periosteum-derived cells maintain phenotypic stability and chondrogenic potential throughout expansion regardless of donor age. Arthritis Rheum 44: 85-95.

De Bari C, Dell'Accio F, Tylzanowski P, Luyten FP (2001b) Multipotent mesenchymal stem cells from adult human synovial membrane. Arthritis Rheum 44: 19281942.

De Bari C, Dell'Accio F, Vanlauwe J, Eyckmans J, Khan IM, Archer CW, Jones EA, McGonagle D, Mitsiadis TA, Pitzalis C, Luyten FP (2006) Mesenchymal multipotency of adult human periosteal cells demonstrated by single-cell lineage analysis. Arthritis Rheum 54: 1209-1221.

Derfoul A, Perkins GL, Hall DJ, Tuan RS (2006) Glucocorticoids promote chondrogenic differentiation of adult human mesenchymal stem cells by enhancing expression of cartilage extracellular matrix genes. Stem Cells 24: 1487-1495.

Erickson GR, Gimble JM, Franklin DM, Rice HE, Awad H, Guilak F (2002) Chondrogenic potential of adipose tissue-derived stromal cells in vitro and in vivo. Biochem Biophys Res Commun 290: 763-769.

Farndale RW, Buttle DJ, Barrett AJ (1986) Improved quantitation and discrimination of sulphated 
glycosaminoglycans by use of dimethylmethylene blue. Biochim Biophys Acta 883: 173-177.

Friedenstein AJ, Piatetzky S, II, Petrakova KV (1966) Osteogenesis in transplants of bone marrow cells. J Embryol Exp Morphol 16: 381-390.

Gross KL, Cidlowski JA (2008) Tissue-specific glucocorticoid action: A family affair. Trends Endocrinol Metab 19: 331-339.

Hauser N, Paulsson M, Heinegard D, Morgelin M (1996) Interaction of cartilage matrix protein with aggrecan. Increased covalent cross-linking with tissue maturation. J Biol Chem 271: 32247-32252.

Hynes RO (2002) Integrins: Bidirectional, allosteric signaling machines. Cell 110: 673-687.

Hynes RO (2009) The extracellular matrix: Not just Pretty fibrils. Science 326: 1216-1219.

Johnstone B, Hering TM, Caplan AI, Goldberg VM, Yoo JU (1998) In vitro chondrogenesis of bone marrowderived mesenchymal progenitor cells. Exp Cell Res 238: 265-272.

Jorgensen NR, Henriksen Z, Sorensen OH, Civitelli R (2004) Dexamethasone, BMP-2, and 1,25-dihydroxy vitamin $\mathrm{D}$ enhance a more differentiated osteoblast phenotype: validation of an in vitro model for human bone marrow-derived primary osteoblasts. Steroids 69: 219-226.

Kato Y, Gospodarowicz D (1985) Stimulation by glucocorticoid of the synthesis of cartilage-matrix proteoglycans produced by rabbit costal chondrocytes in vitro. J Biol Chem 260: 2364-2373.

Kleiman A, Tuckermann JP (2007) Glucocorticoid receptor action in beneficial and side effects of steroid therapy: Lessons from conditional knockout mice. Mol Cell Endocrinol 275: 98-108.

Kurth T, Hedbom E, Shintani N, Sugimoto M, Chen FH, Haspl M, Martinovic S, Hunziker EB (2007) Chondrogenic potential of human synovial mesenchymal stem cells in alginate. Osteoarthritis Cartilage 15: 1178-1189.

Majumdar MK, Wang E, Morris EA (2001) BMP-2 and BMP-9 promotes chondrogenic differentiation of human multipotential mesenchymal cells and overcomes the inhibitory effect of Il-1. J Cell Physiol 189: 275-284.

Mastrogiacomo M, Derubeis AR, Cancedda R (2005) Bone and cartilage formation by skeletal muscle derived cells. J Cell Physiol 204: 594-603.

Miyazaki Y, Tsukazaki T, Hirota Y, Yonekura A, Osaki M, Shindo H, Yamashita S (2000) Dexamethasone inhibition of TGF beta-induced cell growth and type II collagen mrRNA expression through ERK-integrated AP-1 activity in cultured rat articular chondrocytes. Osteoarthritis Cartilage 8: 378-385.

Miyazono K, Kusanagi K, Inoue H (2001) Divergence and convergence of TGF-beta/BMP signaling. J Cell Physiol 187: 265-276.

Na K, Park JH, Kim SW, Sun BK, Woo DG, Chung HM, Park KH (2006) Delivery of dexamethasone, ascorbate, and growth Factor (TGF beta-3) in thermo-reversible hydrogel constructs embedded with rabbit chondrocytes. Biomaterials 27: 5951-5957.

Neame PJ, Barry FP (1993) The link proteins. Experientia 49: 393-402.
Neumann K, Endres M, Ringe J, Flath B, Manz R, Haupl T, Sittinger M, Kaps C (2007) BMP7 promotes adipogenic but not osteo-/chondrogenic differentiation of adult human bone marrow-derived stem cells in highdensity micro-mass culture. J Cell Biochem 102: 626-637.

Nöth U, Osyczka AM, Tuli R, Hickok NJ, Danielson KG, Tuan RS (2002) Multilineage mesenchymal differentiation potential of human trabecular bone-derived cells. J Orthop Res 20: 1060-1069.

Nuttelman CR, Tripodi MC, Anseth KS (2006) Dexamethasone-functionalized gels induce osteogenic differentiation of encapsulated HMSCs. J Biomed Mater Res A 76: 183-195.

Park Y, Sugimoto M, Watrin A, Chiquet M, Hunziker EB (2005) BMP-2 induces the expression of chondrocytespecific genes in bovine synovium-derived progenitor cells cultured in three-dimensional alginate hydrogel. Osteoarthritis Cartilage 13: 527-536.

Pereira RM, Delany AM, Canalis E (2001) Cortisol inhibits the differentiation and apoptosis of osteoblasts in culture. Bone 28: 484-490.

Prowse AB, Chong F, Gray PP, Munro TP (2011) Stem cell integrins: implications for ex vivo culture and cellular therapies. Stem Cell Res 6: 1-12.

Pryce BA, Watson SS, Murchison ND, Staverosky JA, Dunker N, Schweitzer R (2009) Recruitment and maintenance of tendon progenitors by TGFbeta signaling are essential for tendon formation. Development 136: 1351-1361.

Purpura KA, Aubin JE, Zandstra PW (2004) Sustained in vitro expansion of bone progenitors is cell density dependent. Stem Cells 22: 39-50.

Quarto R, Campanile G, Cancedda R, Dozin B (1992) Thyroid hormone, insulin, and glucocorticoids are sufficient to support chondrocyte differentiation to hypertrophy: A serum-free analysis. J Cell Biol 119: 989995.

Retting KN, Song B, Yoon BS, Lyons KM (2009) BMP canonical Smad signaling through Smad1 and Smad5 is required for endochondral bone formation. Development 136: 1093-1104.

Roche S, Ronziere MC, Herbage D, Freyria AM (2001) Native and DPPA cross-linked collagen sponges seeded with fetal bovine epiphyseal chondrocytes used for cartilage tissue engineering. Biomaterials 22: 9-18.

Sakaguchi Y, Sekiya I, Yagishita K, Muneta T (2005) Comparison of human stem cells derived from various mesenchymal tissues: Superiority of synovium as a cell source. Arthritis Rheum 52: 2521-2529.

Sanford LP, Ormsby I, Gittenberger-de Groot AC, Sariola H, Friedman R, Boivin GP, Cardell EL, Doetschman T (1997) TGFbeta2 knockout mice have multiple developmental defects that are non-overlapping with other TGFbeta knockout phenotypes. Development 124: 2659-2670.

Schmitt B, Ringe J, Haupl T, Notter M, Manz R, Burmester GR, Sittinger M, Kaps C (2003) BMP2 initiates chondrogenic lineage development of adult human mesenchymal stem cells in high-density culture. Differentiation 71: 567-577. 
Sekiya I, Koopman P, Tsuji K, Mertin S, Harley V, Yamada Y, Shinomiya K, Nifuji A, Noda M (2001) Dexamethasone enhances Sox 9 expression in chondrocytes. J Endocrinol 169: 573-579.

Sekiya I, Larson BL, Vuoristo JT, Reger RL, Prockop DJ (2005) Comparison of effect of BMP-2, -4, and -6 on in vitro cartilage formation of human adult stem cells from bone marrow stroma. Cell Tissue Res 320: 269-276.

Shintani N, Hunziker EB (2007) Chondrogenic differentiation of bovine synovium: Bone morphogenetic proteins 2 and 7 and transforming growth factor beta1 induce the formation of different types of cartilaginous tissue. Arthritis Rheum 56: 1869-1879.

Shintani N, Kurth T, Hunziker EB (2007) Expression of cartilage-related genes in bovine synovial tissue. J Orthop Res 25: 813-819.

Silbermann M, von der Mark K, Maor G, van Menxel M (1987) Dexamethasone impairs growth and collagen synthesis in condylar cartilage in vitro. Bone Miner 2: 87-106.

Sinanan AC, Hunt NP, Lewis MP (2004) Human adult craniofacial muscle-derived cells: Neural-cell adhesionmolecule (NCAM; CD56)-expressing cells appear to contain multipotential stem cells. Biotechnol Appl Biochem 40: 25-34.

Takano T, Takigawa M, Suzuki F (1985) Stimulation by glucocorticoids of the differentiated phenotype of chondrocytes and the proliferation of rabbit costal chondrocytes in culture. J Biochem 97: 1093-1100.

Tessler RH, Salmon WD, Jr. (1975) Glucocorticoid inhibition of sulfate incorporation by cartilage of normal rats. Endocrinology 96: 898-902.

Weinstein RS, Jilka RL, Parfitt AM, Manolagas SC (1998) Inhibition of osteoblastogenesis and promotion of apoptosis of osteoblasts and osteocytes by glucocorticoids. Potential mechanisms of their deleterious effects on bone. J Clin Invest 102: 274-282.

Yang X, Chen L, Xu X, Li C, Huang C, Deng CX (2001) TGF-beta/Smad3 signals repress chondrocyte hypertrophic differentiation and are required for maintaining articular cartilage. J Cell Biol 153: 35-46.

Yoo JU, Barthel TS, Nishimura K, Solchaga L, Caplan AI, Goldberg VM, Johnstone B (1998) The chondrogenic potential of human bone-marrow-derived mesenchymal progenitor cells. J Bone Joint Surg Am 80: 1745-1757.

Yoshimura H, Muneta T, Nimura A, Yokoyama A, Koga H, Sekiya I (2007) Comparison of rat mesenchymal stem cells derived from bone marrow, synovium, periosteum, adipose tissue, and muscle. Cell Tissue Res 327: 449-462.

Zuk PA, Zhu M, Ashjian P, De Ugarte DA, Huang JI, Mizuno H, Alfonso ZC, Fraser JK, Benhaim P, Hedrick MH (2002) Human adipose tissue is a source of multipotent stem cells. Mol Biol Cell 13: 4279-4295.

\section{Discussion with Reviewers}

Reviewer I: Given your data what would you recommend as "optimal" culture conditions for each group tested (i.e synovial explants, synovial aggregates, bone-marrow- derived MSCs aggregates)? Overall, which system would you recommend?

Authors: When using synovial MSCs (explants or aggregates), BMP-2 can stimulate the deposition of both aggrecan and type-II collagen, whereas TGF- $\beta 1$ can induce the accumulation of aggrecan to a like degree but not that of type-II collagen. These findings indicate that BMP-2 drives chondrogenesis in a direction that yields a hyaline type of articular cartilage (abundance of type-II collagen and aggrecan), whereas TGF- $\beta 1$ drives the process in one that yields a fibrocartilaginous type of tissue (low levels of type-II collagen and an abundance of aggrecan). Thus, from the point of view of reconstituting articular cartilage from synovial MSCs (explants or aggregates), BMP-2 is a more appropriate chondroinductive agent than TGF- $ß 1$. The findings of the present study indicate that, in the case of synovial explants, DEX should not be included in the chondrogenic medium; in the case of aggregates of synovial MSCs, DEX can be dispensed with, although it can enhance the deposition of aggrecan. When using aggregates of bone-marrow-derived MSCs, optimal chondrogenic differentiation can be achieved after stimulation with TGF- $\beta 1$ in the presence of DEX.

Since each of the three systems has its advantages and disadvantages, it is difficult to recommend one in particular. But from the standpoint of dispensing with DEX, we would advocate synovial explants as a system and BMP-2 as the chondroinductive agent.

Reviewer I: In Fig. 3A there was a change in cell shape between passage 0 and passage 1 for bone-marrow derived MSCs. Do you think this is a function of not including FGF2, as is often included in the medium for passaged BM-MSCs?

Authors: We have no personal experience with the use of FGF-2 in the culturing of bone-marrow-derived MSCs. However, Solchaga et al. (Solchaga et al., 2005) have reported the sizes of human bone-marrow-derived MSCs to be smaller in the presence than in the absence of this agent during the first passage. It is thus conceivable that the change in cell shape and the increase in cell size that we observed between passage 0 and passage 1 reflect the absence of FGF-2. In the present study, the bone-marrowderived MSCs were expanded in the absence of FGF-2, in accordance with the methodology described by Johnstone et al. (Johnstone et al., 1998).

Reviewer I: Considering both your gene and protein data, which gene patterns were the strongest indicators of good cartilage matrix deposition?

Authors: Since immunohistochemistry was performed only for type-II collagen and aggrecan, we cannot answer this question categorically. However, we would venture to say that the expression not only of the gene for aggrecan but also that for type-II-collagen is indispensable for the formation of a hyaline type of cartilage matrix. As our data for TGF- $ß 1$-stimulated synovial MSCs reveal, the expression of type-II collagen gene and the deposition of the protein itself do not necessarily go hand in hand with those for aggrecan. In the literature, Sox 9 is usually 
considered to be a specific marker of chondrogenesis, for which process it is indispensable. However, expression of the Sox9 gene does not necessarily indicate that a cartilaginous matrix has been deposited. The findings of the present study indicate that the Sox 9 gene can be up-regulated even if the genes for other markers of a cartilaginous matrix (collagen types II, IX and XI, aggrecan, COMP and link protein) are down-regulated and if the deposition of type-II collagen and aggrecan are attenuated, as evidenced for synovial explants that had been stimulated with BMP-2 in the presence of DEX. Hence, no single gene can alone be used as a marker of a hyaline type of articular cartilage.

\section{Additional References}

Johnstone B, Hering TM, Caplan AI, Goldberg VM, Yoo JU (1998) In vitro chondrogenesis of bone marrowderived mesenchymal progenitor cells. Exp Cell Res 238: 265-272.

Solchaga LA, Penick K, Porter JD, Goldberg VM, Caplan AI, Welter JF (2005) FGF-2 enhances the mitotic and chondrogenic potentials of human adult bone marrowderived mesenchymal stem cells. J Cell Physiol 203: 398409. 